\title{
INTERPRETAÇÃO DOS CONTRATOS Os limites de cobertura dos planos de saúde
}

\author{
Tese de doutorado \\ Orientador: Professor Titular Dr. Ronaldo Porto Macedo Junior \\ Coorientadora: Professora Dra. Maria Paula da Costa Bertran
}

UNIVERSIDADE DE SÃO PAULO

FACULDADE DE DIREITO

São Paulo-SP

2020 


\section{INTERPRETAÇÃO DOS CONTRATOS Os limites de cobertura dos planos de saúde}

Tese apresentada a Banca Examinadora do Programa de Pós-Graduação em Direito, da Faculdade de Direito da Universidade de São Paulo, como exigência parcial para obtenção de título de Doutor em Direito, na área de concentração Filosofia e Teoria Geral do Direito, sob orientação do Professor Titular Dr. Ronaldo Porto Macedo Junior e coorientação da Professora Doutora Maria Paula da Costa Bertran. 
Catalogação da Publicação

Serviço de Biblioteca e Documentação

Faculdade de Direito da Universidade de São Paulo

Biazevic, Juan Paulo Haye

Interpretação dos contratos: os limites de cobertura dos planos de saúde; Juan Paulo Haye Biazevic ; orientador Ronaldo Porto Macedo Junior -São Paulo, 2020.

266

Tese (Doutorado - Programa de Pós-Graduação em Filosofia do Direito e Teoria Geral do Direito) Faculdade de Direito, Universidade de São Paulo, 2020 .

1. Teoria geral dos contratos. 2. Interpretação dos contratos. 3. Contratos relacionais e descontínuos. 4. Análise econômica do direito. I. Macedo Junior, Ronaldo Porto, orient. II. Título. 


\section{FOLHA DE AVALIAÇÃO}

NOME: Juan Paulo Haye Biazevic.

TÍTULO: Interpretação dos contratos: os limites de cobertura dos planos de saúde.

Tese apresentada à Faculdade de Direito da Universidade de São Paulo para obtenção de título de doutor em direito.

Aprovado em:

\section{BANCA EXAMINADORA}

Prof. Titular Ronaldo Porto Macedo Junior

Julgamento:

Prof. Instituição:

Julgamento: Assinatura:

Prof. Instituição:

Julgamento: Assinatura:

Prof. Instituição:

Julgamento: Assinatura:

Prof. Instituição:

Julgamento: Assinatura: 
A meus pais, por me mostrar o caminho.

A minhas filhas, por me dar coragem para segui-lo.

A minha esposa, por me guiar nos momentos mais difíceis.

Que todos tenham saúde para viver uma vida digna de ser vivida. 


\section{AGRADECIMENTOS}

Confesso-me devedor de tantas pessoas e instituições que temo não ser capaz de lembrá-las ou prestar-lhes a devida homenagem neste pequeno espaço. Este trabalho representa o encerramento de um longo ciclo de estudos, ciclo que teve início no ano de 2012, com a inscrição no processo seletivo para o ingresso no programa de mestrado da Faculdade de Direito da Universidade de São Paulo. O ano de 2012 também foi o ano de nascimento de minha primeira filha, Maria Luísa. A família cresceu durante a jornada. Cecília nasceu em 2015, ano no qual escrevi a dissertação sobre a evolução da teoria do raciocínio jurídico de Neil MacCormick. Hoje Maria Luísa já tem 7 anos e Cecília está há menos de um mês de completar 5. Foram muitos anos tentando compatibilizar os papeis de estudante, pesquisador, pai, marido, filho e juiz. Anos de aprendizado, realizações e dificuldades. Não teria sido capaz de alcançar o ponto final do caminho sem a contribuição das pessoas e das instituições que abaixo recordo, sempre correndo o risco de ser injusto por algum esquecimento.

Devo iniciar por meu orientador no mestrado e no doutorado, pois com ele tenho dívida de gratidão impagável. Ronaldo Macedo é um daqueles raros professores que ensinam não só uma área do conhecimento, mas a própria maneira pela qual se deve ensinar. O cuidado extremo na elaboração dos programas, a forma instigante pela qual incentiva o enfrentamento de textos complexos e a disposição quase infinita para esclarecer cada dúvida, mesmo as mais simples, fizeram dos anos que tive o prazer de ser seu aluno anos inesquecíveis. Meu aprendizado ultrapassou muito as esferas da filosofia e de teoria geral do direito e alcançou a própria maneira pela qual devemos nos engajar nas tarefas de estudar e ensinar. Aqui não posso ir além de dizer "muito obrigado por tudo", o que, embora simples, é o que este espaço me permite. O leitor perceberá a influência dos diversos trabalhos do Professor no decorrer do texto, em especial nos Capítulos 1 e 3 .

Agradeço também minha coorientadora no doutorado, a Professora Maria Paula Bertran. Aprendi muito com nossas conversas em teoria dos contratos e com sua leitura atenta das versões preliminares deste trabalho. Beneficiei-me das suas ideias sobre comutatividade nos contratos, em especial por ocasião da leitura de sua tese sobre justiça contratual.

Sou devedor também da Universidade de São Paulo, instituição pública responsável por minha formação acadêmica desde a graduação. Os anos que tive o prazer de frequentar 
o Largo de São Francisco foram inspiradores. O Largo é uma escola dentro da escola, no qual a convivência humana é tão ou mais enriquecedora do que a experiência acadêmica. Ali fiz grandes amigos e tomei contato com ideias plurais. O contraste entre mundos, em especial entre as ideias debatidas na academia e a realidade do centro de São Paulo, me instigou a repensar a relação entre o país que queremos ter e o direito que devemos construir para realizar o projeto.

Também sou grato a outra grande instituição deste Estado, o Egrégio Tribunal de Justiça. O exercício da magistratura é uma escola única, um locus que sinaliza parte relevante das disfuncionalidades da nossa sociedade. Sem dúvida, foram as complexidades enfrentadas durante o exercício da magistratura que me obrigaram a desafiar e repensar parte substantiva dos fundamentos metodológicos pelos quais a tarefa de raciocinar juridicamente, que nada mais é do que aplicar o direito a casos concretos, opera. Sou especialmente grato aos servidores dos Juizados Especiais de Bragança Paulista e Vinhedo, que me acompanharam na última década e demonstraram que pessoas comprometidas podem fazer grandes coisas mesmo em contextos de escassez de recursos.

Agora a família. Meus pais sempre foram meu exemplo de luta e perseverança. Mesmo com nada mais do que a força de trabalho, decidiram imigrar ao Brasil na busca de uma vida melhor. Com muito esforço, criaram seus filhos e tiveram uma vida admirável. Eles são minha fonte de inspiração e não tenho como agradecer-lhes tudo o que fizeram por todos nós.

Agradeço minha esposa Luciana, minha parceira de vida há quase 14 anos. Vivemos muitas coisas maravilhosas e enfrentamos juntos nossas dificuldades. Mesmo tendo sofrido com minha escassez de tempo, sempre esteve ao meu lado incentivando meus objetivos. Sua compreensão e amor foram fundamentais nestes anos e, sem eles, a jornada teria sido certamente mais dura. Obrigado por estar ao meu lado.

Finalmente, tenho que agradecer minhas filhas, Maria Luísa e Cecília. Aqui repito algo que escrevi para Maria Luísa por ocasião de sua "formatura" no ensino infantil, mas que reflete o que desejo para ambas. Estudar é importante, porque nos dá liberdade para escolher o que queremos ser, mas é o amor que nos fornece o propósito para seguir em frente. Estudem para ser livres, amem para ser felizes. Liberdade e felicidade é o que lhes desejo nesta vida. Obrigado por terem me permitido voltar a ser criança e esquecer, ainda que brevemente, todos os deveres que a vida adulta nos encarga cogentemente. 


\section{RESUMO}

BIAZEVIC, Juan Paulo Haye. Interpretação dos contratos: os limites de cobertura dos planos de saúde. 2020. 266p. Tese de Doutorado (Direito) - Faculdade de Direito, Universidade de São Paulo, São Paulo, 2020.

O objetivo deste trabalho foi o de determinar, a partir dos valores que conferem sentido ao contrato de plano de saúde, os limites daquilo que os contratantes podem exigir das operadoras. No plano da filosofia geral, defendi que o direito é uma prática social complexa composta por diversos jogos de linguagem, à semelhança do que defendia, para as práticas sociais, Ludwig Wittgenstein na última fase de seu pensamento. No plano da teoria geral do direito, a metodologia de Ronald Dworkin foi utilizada para determinar a forma interpretativa pela qual devemos compreender o funcionamento de cada uma de suas instâncias paradigmáticas, o que envolve afirmar não ser possível compreender o funcionamento dos conceitos em geral, tal como o conceito de contrato, sem levar em conta os valores de moral política que o tornam valioso para seus participantes. Os contratos de planos de saúde devem ser considerados contratos relacionais, pois são contratos que vigem por longos períodos e nos quais as obrigações reciprocamente devidas se modificam à medida que evolui o conhecimento técnico-científico na área da saúde. Defendi que a saúde importa moralmente pelas oportunidades que proporciona às pessoas para viver uma vida digna. Diversos valores justificam a necessidade de regulação estatal no funcionamento do contrato, tais como a importância moral da saúde e da socialização dos infortúnios, a disparidade de forças entre as partes do contrato e a necessidade de constante atualização do conceito de adimplemento perfeito do contrato relacional. A partir da maneira pela qual argumentos econômicos podem participar do raciocínio jurídico, defendi que o contratante tem o direito, a partir do conceito estruturante de comutatividade, de receber não só aquilo que foi expressamente contratado ou imposto através da regulação, mas todo e qualquer procedimento com custo-efetividade semelhante a procedimento já regulamentado a partir de critérios determinados pela economia da saúde e pela medicina baseada em evidências.

Palavras-chave: Teoria geral dos contratos. Interpretação dos contratos. Contratos relacionais e descontínuos. Análise econômica do direito. 


\begin{abstract}
BIAZEVIC, Juan Paulo Haye. Interpretation of contracts: health insurance coverage limits. 2020. 266p. Thesis (Doctor in Law) - Faculty of Law, University of São Paulo, São Paulo, 2020.

The purpose of this work was to determine, based on the values that give meaning to the health insurance contract, the limits of what policyholders may require from insurers. In terms of general philosophy, I argued that law is a complex social practice composed of various language games, as Ludwig Wittgenstein argued for social practices in the last phase of his thinking. In terms of the jurisprudence, Ronald Dworkin's methodology was used to determine the interpretative way in which we must understand the functioning of each of its paradigmatic instances, which involves stating that it is not possible to understand the functioning of concepts in general, as the concept of contract, disregarding the values of political morality that make it valuable to its participants. Health insurance contracts must be considered relational contracts, as they are long-term contracts in which the obligations due to each other change as the technical-scientific knowledge in the health field evolves. I argued that health matters morally due to the opportunities that it provides to people to live a dignified life. Several values justify the need for state regulation in the operation of the contract, such as the moral importance of the health and the socialization of misfortunes, the disparity of forces between the parties and the need for constant updating of the concept of perfect performance of the relational contract. From the way in which economic arguments can participate in legal reasoning, I argued that the policyholders have the right, from the structuring concept of commutativity, to receive not only what was expressly contracted or imposed through regulation, but any procedure with cost-effectiveness similar to a procedure already regulated based on criteria determined by the health economy and the evidencebased medicine.
\end{abstract}

Keywords: General theory of contracts. Interpretation of contracts. Relational and discrete contracts. Economic analysis of law. 


\section{RIASSUNTO}

BIAZEVIC, Juan Paulo Haye. Interpretazione dei contratti: limiti di copertura della polizza sanitaria. 2020. 266p. Tesi de Dottorato - Facoltà di Diritto, Università di San Paolo, San Paolo, 2020.

L'obiettivo del presente lavoro è stato quello di stabilire, a partire dai valori che attribuiscono senso al contratto della polizza sanitaria, i limiti di ciò che i contrattanti possono esigere dalle compagnie. Sul piano della filosofia generale, ho sostenuto che il diritto sia una pratica sociale complessa composta da diversi giochi di linguaggio, a somiglianza di quanto sosteneva Ludwig Wittgenstein per le pratiche sociali nell'ultima fase del suo pensiero. Sul piano della teoria generale del diritto, la metodologia di Ronald Dworkin è stata utilizzata al fine di determinare la forma interpretativa attraverso la quale dobbiamo comprendere il funzionamento di ognuna delle sue istanze paradigmatiche, il che significa affermare l'impossibilità di comprendere il funzionamento dei concetti in generale, tali come il concetto di contratto, senza tenere conto dei valori di morale politica che lo rendono prezioso ai suoi partecipanti. I contratti della polizza sanitaria vanno considerati contratti relazionali perché sono contratti a lungo termine nei quali le obbligazioni reciprocamente dovute si modificano a misura che evoluisce la conoscenza tecnicoscientifica nell'area medica. Ho sostenuto che la salute importa moralmente per le opportunità che offre alle persone di vivere una vita degna. Diversi valori giustificano la necessità di regolazione statale nel funzionamento del contratto, tali come l'importanza morale della salute e della socializzazione degli infortuni, la disparità di forze tra le parti del contratto e la necessità di costante aggiornamento del concetto di adempimento perfetto del contratto relazionale. A partire dal modo attraverso il quale argomenti economici possono far parte del ragionamento giuridico, ho sostenuto che il contrattante ha il diritto, a partire dal concetto strutturante di commutatività, di ricevere non soltanto quello che è stato espressamente contrattato o imposto dalla regolazione, ma ogni qualsivoglia procedimento con costo-effettività simile a procedimento già regolamentato a partire da criteri determinati dall'economia della salute e dalla medicina basata sulle evidenze.

Parole chiavi: Teoria generale dei contratti. Interpretazione dei contratti. Contratti relazionali e discontinui. Analisi economica del diritto. 


\section{SUMÁRIO}

INTRODUÇÃO

1. Apresentando a questão ............................................................................ 1

2. O contrato de plano de saúde: uma primeira abordagem.....................................

2.1. Os valores que conferem sentido aos planos de saúde.................................6

2.2. Calculando o preço devido ......................................................................9

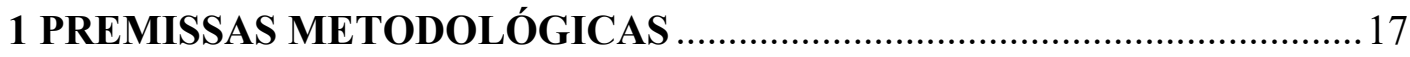

1.1 A objetividade das proposições jurídicas......................................................... 19

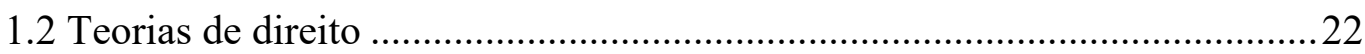

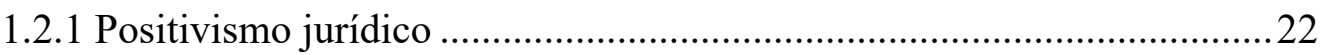

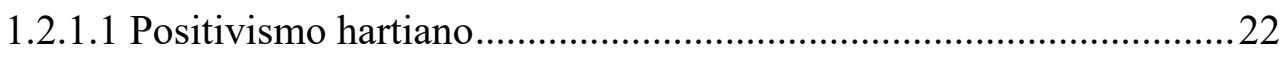

1.2.1.2 As primeiras críticas de Dworkin...................................................29

1.2.1.3 As respostas de Hart e as réplicas de Dworkin .................................35

1.2.2 Direito como prática interpretativa .............................................................

1.3 A diversidade dos critérios de verdade .......................................................51

1.4 A integridade como ideal decisório ……………………………………....5

1.5 Direito civil constitucional e prioridade local..................................................... 64

1.6 A gramática dos limites de cobertura nos planos de saúde...............................68

1.6.1 Justiça distributiva e limites de cobertura ..................................................71

1.6.2 Rejeitando o modelo universal de cobertura.............................................75

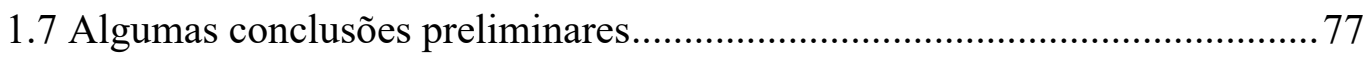

2 CONTRATO COMO CONCEITO INTERPRETATIVO ……………..........79

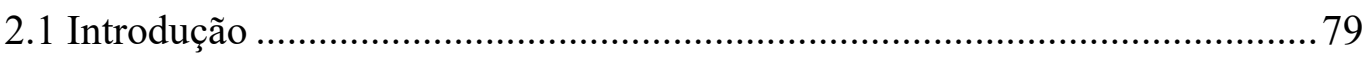

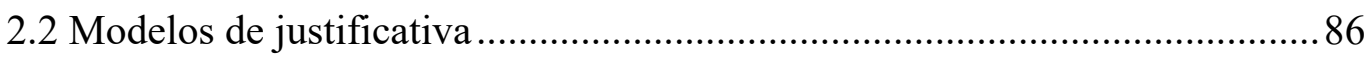

2.2.1 Justiça comutativa e justiça distributiva...................................................... 88

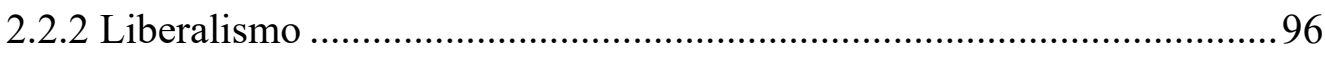

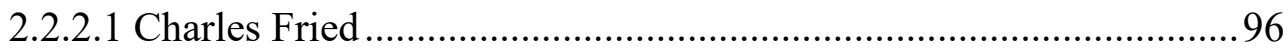




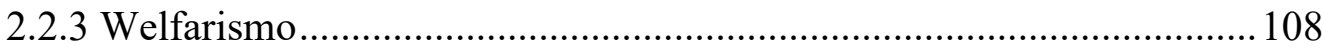

2.2.3.1 Estado welfarista ........................................................................... 110

2.2.3.2 Contrato welfarista ..................................................................... 113

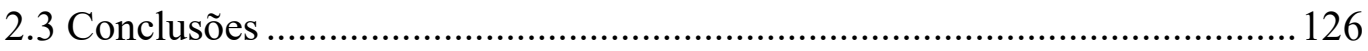

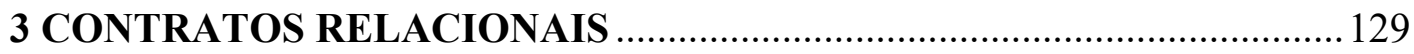

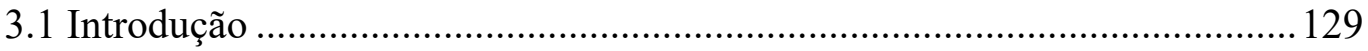

3.2 A justificativa relacional para o direito dos contratos................................... 131

3.3 Contratos descontínuos e contratos relacionais .............................................136

3.3.1 Raízes primárias dos contratos............................................................137

3.3.2 Características paradigmáticas................................................................ 141

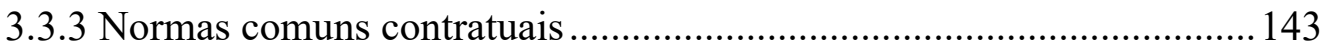

3.4 Interpretação em contratos descontínuos e em contratos relacionais ...........146

3.5 Características relacionais dos planos de saúde.............................................. 153

4 ASPECTOS REGULATÓRIOS E ECONÔMICOS DO CONTRATO.......157

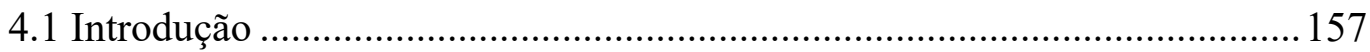

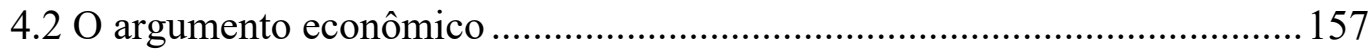

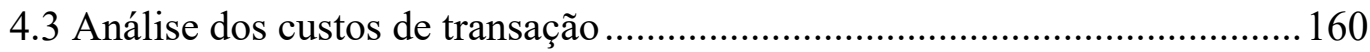

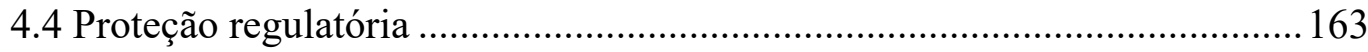

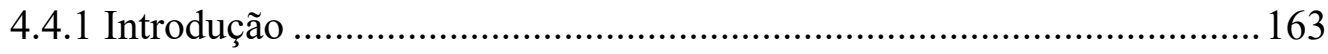

4.4.2 Justificativas econômicas ....................................................................... 167

4.4.3 Justificativas não econômicas ............................................................... 171

4.4.4 Regulação e o adimplemento do contrato ............................................... 175

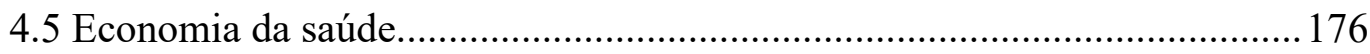

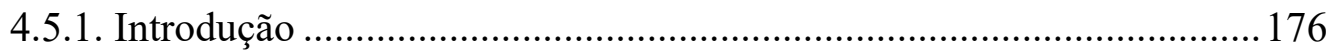

4.5.2. Fatores de majoração dos custos em saúde............................................ 178

4.5.3 A introdução de novas tecnologias ............................................................ 184

4.5.3.1 Aspectos gerais da incorporação.....................................................185 
4.5.3.2 Critérios de incorporação

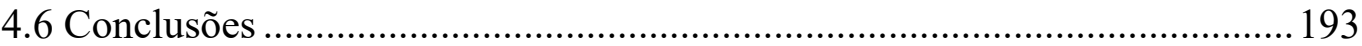

5 COBERTURA RELACIONAL PARA PLANOS DE SAÚDE...................... 195

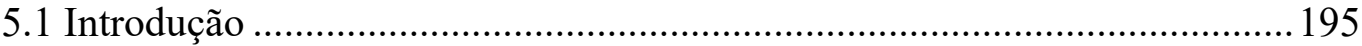

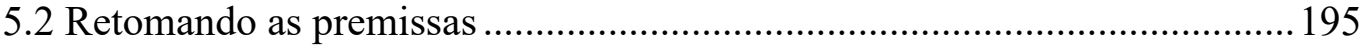

5.3 Justificando moralmente a padronização de coberturas................................201

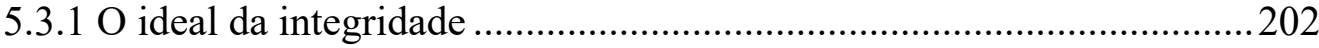

5.3.2 A importância moral da proteção à saúde...........................................208

5.3.3 A solução procedimental para a legitimidade da regulação..................211

5.4 Desafiando argumentativamente o conteúdo do rol.................................220

5.4.1 O modelo universal de cobertura .......................................................22

5.4.2 O modelo convencional de cobertura................................................221

5.4.3 O modelo relacional de cobertura ......................................................222

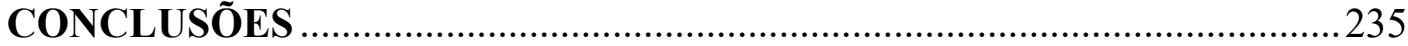

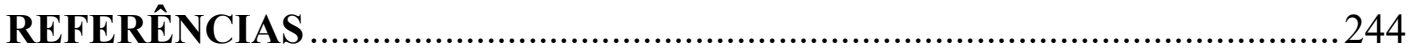




\section{INTRODUÇÃO}

\section{Apresentando a questão}

Debater os limites de cobertura dos planos de saúde é um tema de interpretação em direito dos contratos. Nesse campo, como analisarei com mais detalhes ao longo do texto, grandes e importantes são as divergências no plano dos limites daquilo que os usuários podem exigir das operadoras. Há os que defendam que as operadoras devam custear todo e qualquer procedimento e os que limitam essa pretensão àquilo que possui base em algum tipo de convenção. A existência de duas posições tão antagônicas invoca não apenas questões sobre a possibilidade de objetividade no campo do direito, mas pontos complexos sobre ontologia, metodologia, economia da saúde, regulação e filosofia moral. O objetivo deste trabalho é analisar, pelo prisma da teoria geral do direito, os diversos conceitos que conferem sentido à lógica de funcionamento do contrato de plano de saúde. Embora o título possa sugerir o contrário, este não é um trabalho propriamente de dogmática jurídica. É um trabalho de teoria geral que busca esclarecer os pontos relevantes da gramática que confere sentido às diversas categorias que disciplinam esse contrato ${ }^{1}$. Por exemplo, não é possível entender como a boa-fé objetiva e a tutela das expectativas legítimas operam sem compreender, antes, a maneira pela qual se relacionam questões como os valores do welfarismo, a importância da regulação, os desafios da introdução de novas tecnologias na área da saúde e o decurso do tempo em um contrato que se supõe deva viger por décadas.

Trabalharei sob a seguinte hipótese: existe uma incompreensão, entre usuários, operadoras de planos de saúde e alguns profissionais do direito acerca da gramática que confere sentido ao contrato de plano de saúde. Essa incompreensão é a fonte dos debates quanto aos limites de cobertura. $\mathrm{O}$ dissenso interpretativo não se resume a esse ponto, mas entendo que ele merece especial atenção por ser absolutamente central para o conceito de adimplemento perfeito desse contrato. As pessoas celebram contratos com operadoras de

\footnotetext{
1 Utilizo o termo gramática tal como empregado por Wittgenstein na última fase de suas obras: o conjunto de regras que confere sentido ao uso das palavras dentro da estrutura de uma prática linguística. A linguagem aqui é considerada como um fenômeno que se altera no tempo e no espaço, adquirindo sentido dentro de um determinado jogo, no caso que me interessa, no interior do jogo de linguagem da prática jurídica (WITTGENSTEIN, Ludwig. Philosophical investigations. 4th ed. Oxford: Wiley-Blackwell, 2009, p. 47 e 52). Sobre o tema, vide MCGINN, Marie. Routledge philosophy guidebook to Wittgenstein and the philosophical investigations. London: Routledge, 1997, p. 13-4. No decorrer do texto utilizarei como sinônimas as expressões lógica e gramática.
} 
planos de saúde para afastar o risco de ter de custear integralmente, com recursos próprios, os tratamentos necessários para enfrentar certos eventos em saúde. É importante, considerando essa expectativa de cobertura, compreender o que se pode exigir das operadoras dentro dos limites das fontes de direito existentes. Como afirmei no início, duas são as posições antagônicas sobre o assunto.

A primeira posição defende um modelo de cobertura universal. As decisões judiciais que adotam esse modelo, em geral, sustentam que os usuários possuem uma expectativa legítima de cobertura, consistente no direito de exigir o custeio de todo e qualquer procedimento reconhecido pela comunidade médica. As pessoas contratam planos de saúde para obter cobertura no caso de sinistro e os direitos à vida e à saúde dos usuários não poderiam ser prejudicados pela inércia da Agência Nacional de Saúde (ANS) em atualizar a lista de procedimentos obrigatórios ${ }^{2}$. Assim, a intervenção judicial se justificaria para corrigir uma falha regulatória, consistente na falta de correspondência exata entre aquilo que é considerado eficaz pela comunidade dos médicos e a lista de procedimentos obrigatórios da $\mathrm{ANS}^{3}$.

A segunda posição defende um modelo de cobertura convencional. Ela sustenta que apenas tratamentos com previsão em algum tipo de convenção - a legislação, a regulação ou o contrato - podem ser exigidos pelo usuário dos serviços de planos de saúde. Afinal, vivemos em um Estado de Direito, Estado que reconhece o poder do Legislativo e da ANS de disciplinar o rol de procedimentos obrigatórios e o poder das pessoas de criar livremente obrigações recíprocas. Para além desse rol e dos limites do que foi livremente contratado, os usuários não teriam o que exigir juridicamente.

A pergunta que pretendo responder, portanto, é a seguinte: considerando a gramática de funcionamento do contrato de plano de saúde, o usuário pode exigir da operadora o custeio de tratamento não previsto expressamente na regulação ou no contrato? Aqui tomo

\footnotetext{
${ }^{2}$ BRASIL. Tribunal de Justiça do Estado de São Paulo. Apelação n ${ }^{\circ}$ 0104418-97.2011.8.26.0100, 2a Câmara de Direito Privado, São Paulo/SP, 19 de junho de 2012. Disponível em: $<$ https://esaj.tjsp.jus.br/cjsg/consultaCompleta.do?f=1>. Acesso em: 16 de julho de 2018 .

${ }^{3}$ Aqui é paradigmático o enunciado da Súmula $n^{\circ} 102$ do Tribunal de Justiça do Estado de São Paulo, que afirma que "Havendo expressa indicação médica, é abusiva a negativa de cobertura de custeio de tratamento sob o argumento da sua natureza experimental ou por não estar previsto no rol de procedimentos da ANS" (BRASIL. Tribunal de Justiça do Estado de São Paulo. Súmula n ${ }^{\circ}$ 102, São Paulo/SP, 28 de fevereiro de 2013. Disponível em <https://www.tjsp.jus.br/Download/Portal/Biblioteca/Biblioteca/Legislacao/SumulasTJSP. pdf $>$. Acesso em 16 de dezembro de 2019. Note que o enunciado sumulado é ainda mais ampliativo, pois inclui tratamentos experimentais.
} 
o termo regulação de forma ampla, para abranger tanto a legislação ordinária como os atos normativos expedidos pela Agência Nacional de Saúde.

A resposta provisória à questão, que receberá algumas qualificações e maiores explicações no decorrer do trabalho, é a seguinte: considerando todos os valores que concorrem para conferir sentido à gramática de funcionamento desse contrato, o usuário terá o direito de exigir a realização de procedimento fora desses limites desde que, dentro de critérios ditados pela economia da saúde, o novo procedimento apresente custo-efetividade não inferior à custo-efetividade do procedimento já regulamentado. Chamarei essa proposta de modelo de cobertura relacional. Essa é uma resposta que se localiza entre os dois extremos marcados pelos modelos universal e convencional de cobertura. A sua possibilidade depende da compreensão do contrato a partir de três pilares lógico-valorativos: welfarismo, economia da saúde e contratos relacionais.

O primeiro pilar - welfarismo - sustenta que o direito contratual contemporâneo pode adotar medidas, em alguns contextos específicos, para equilibrar as forças concretas das partes dentro de uma relação contratual. Nesses termos, o Estado estará autorizado a interferir em negócios entre particulares sempre que entender necessário em razão da disparidade de forças econômicas ou técnicas entre os contratantes. Aqui, considerações de justiça distributiva (como melhor alocar os recursos disponíveis arrecadados dos usuários dos planos) e de justiça comutativa (o que os usuários podem exigir pelo simples fato de serem contratantes) concorrerão para determinar o que o usuário pode exigir das operadoras.

O segundo pilar - economia da saúde - parte da premissa de que os recursos disponíveis para a manutenção dos contratos são limitados e desenvolve uma série de considerações para fazer o melhor possível com aquilo que as pessoas estão dispostas a reservar para a atenção à saúde. O pilar vai além da questão inicial da necessidade da manutenção de um equilíbrio atuarial. Ele alcança os critérios pelos quais novas tecnologias, normalmente mais caras e não substitutivas das tecnologias anteriores, serão incorporadas aos serviços de saúde em geral. Ele tenta determinar critérios sobre o que se irá incorporar e o que não se incorporará aos serviços de saúde. Trabalharei com a hipótese de que é possível emprestar para a saúde suplementar critérios semelhantes de incorporação utilizados para a saúde pública, pois ambos os sistemas, a despeito de algumas diferenças, lidam com dois problemas em comum: a escassez de recursos e a necessidade quase infinita dos seus usuários.

Finalmente, o último pilar - contratos relacionais - reconhece que existe um conjunto de contratos que demanda tratamento diferenciado em razão do fator tempo. Em contratos 
instantâneos, como a compra de um produto perecível para consumo imediato, o decurso do tempo não apresenta desafios jurídicos. Em outros contratos, como nos contratos de plano de saúde, o passar do tempo introduz complexidades que devem ser equacionadas se se pretende que o contrato possa ser cumprido tal como desejado pelas partes desde a assinatura. Por exemplo, aquilo que se considerava adimplemento perfeito de um contrato de plano de saúde há 20 anos não pode servir como parâmetro de perfeição para o momento atual. A evolução do conhecimento médico e a introdução de novas tecnologias exige que o vínculo contratual seja renovado constantemente, não só pelo prisma das operadoras (com a redefinição daquilo que elas são obrigadas a prestar), mas também pelo prisma dos usuários (com a redefinição do valor que eles terão de pagar). A teoria dos contratos relacionais apresenta boas ferramentas para lidar com as consequências geradas pelo decurso do tempo.

A compreensão dos três pilares pressupõe a articulação dos argumentos a partir de alguma teoria geral do direito. A questão metodológica deve se fazer presente, porquanto parte das incompreensões interpretativas que imputei no início desta introdução, entendo, também decorrem de uma má compreensão da maneira pela qual a prática social do direito se desenvolve. Aqui adotarei um modelo dworkiniano de teoria geral, que compreende o direito como uma prática social interpretativa. A escolha não é arbitrária. Como espero que fique claro na leitura do primeiro capítulo, optar por essa teoria não é propriamente escolher uma entre diversas teorias disponíveis ao mero sabor das conveniências. Há boas razões metodológicas para compreender essa teoria como o relato mais completo e coerente, nos campos descritivo e valorativo, da maneira pela qual nossas práticas interpretativas operam. Ademais, a própria resposta à pergunta formulada já carrega consigo uma rejeição aos modelos positivistas de teoria do direito, pois um positivista coerente não poderia reconhecer a existência de direitos individuais sem a exata correspondência com as regras editadas pelas autoridades do sistema ou criadas consensualmente pelas partes através de um contrato.

Essa pretensão metodológica deve ser compreendida em seus termos exatos. $\mathrm{O}$ trabalho está desenvolvido na premissa de que existe uma metodologia adequada para a interpretação das práticas jurídicas. Essa metodologia é flexível à gramática de funcionamento de cada uma das pequenas parcelas que, reunidas em um todo, identificamos como sendo o direito de uma comunidade. Embora possa parecer abstrato afirmar que a interpretação de proposições deve levar em conta suas manifestações paradigmáticas compreendidas interpretativamente, essa é uma afirmação que aponta alguns caminhos práticos preciosos. Para a infelicidade dos que procuram respostas rápidas para questões complexas, não é possível dispensar do estudo do direito dos contratos questões 
metodológicas, filosóficas e econômicas. Todas atuam em conjunto para determinar como lidar com os problemas que essa prática enfrenta no cotidiano. O objetivo deste trabalho é, ao longo do percurso necessário para responder a questão inicialmente proposta, tentar ilustrar como deve operar o método interpretativo aplicado ao direito dos contratos. Caberá ao leitor, ao final, julgar se fui capaz de cumprir o objetivo.

\section{O contrato de plano de saúde: uma primeira abordagem}

Parece-me útil analisar, desde logo e ainda que em linhas mais gerais, como opera o contrato de plano de saúde. É importante que o leitor já tenha em mente parte da gramática de funcionamento desse contrato. Afinal, algumas das questões sobre as quais me aprofundarei nos próximos capítulos pressupõem a compreensão dos conceitos centrais dessa prática contratual. O objetivo desta seção é compreender dois pontos: (a) o que torna o contrato valioso para os participantes da prática contratual; e (b) como é feito o cálculo do preço cobrado pelas operadoras.

Há de se destacar, de início, que existem enormes semelhanças entre os planos de saúde e os contratos de seguro em geral, notadamente em seus aspectos técnicos, atuariais e financeiros. Os seguros em geral são contratos que buscam indenizar a ocorrência de eventos imprevisíveis que impactam negativamente a vida dos segurados e beneficiários. Para tanto, os contratos estabelecem os riscos que serão protegidos, os limites da proteção, o prazo de vigência e o prêmio a ser pago à seguradora para a assunção dos riscos. Uma característica central para a gramática de funcionamento do contrato está na criação de provisão técnica e capital mínimo por parte da seguradora para enfrentar as despesas. Isso impõe ao usuário do seguro que realize pagamentos antecipados para que, com esse fundo, a seguradora possa indenizar os sinistros verificados ${ }^{4}$. O contrato de plano de saúde, por sua vez, tem como propósito cobrir as despesas associadas a doenças e acidentes pessoais que afetam a saúde do usuário. Parte substantiva desses apuros é incerta, embora algumas despesas, como a

\footnotetext{
${ }^{4}$ Há um ponto que atinge os planos de saúde e que não ocorre nos contratos de seguro: nos planos de saúde não existe limite máximo para a indenização a ser paga. Ao contrário de um seguro de carro, por exemplo, no qual o valor do veículo determina o pagamento máximo, nos planos de saúde não se sabe antecipadamente o valor que será pago em cada internação de usuário.
} 
realização de consultas preventivas, não tenha a mesma característica da aleatoriedade ${ }^{5}$ O contrato é oneroso: enquanto a operadora assume a obrigação de arcar com os ônus financeiros relacionados com o evento coberto, a obrigação do consumidor é a contraprestação em pecúnia do valor estipulado pelo plano ou pelo prêmio pago antecipadamente ${ }^{6}$. É com a realização desses pagamentos que a operadora criará seu fundo para o pagamento das despesas com os sinistros. Fica claro, portanto, que em seus elementos mais essenciais, ambos os contratos compartilham a mesma estrutura gramatical ${ }^{7}$.

\subsection{Os valores que conferem sentido aos planos de saúde}

A semelhança entre os dois contratos permite analisar a questão dos valores que conferem sentido ao plano de saúde através do contrato de seguro. Como esclarece Ewald, o seguro surgiu como uma necessidade pós-feudal, para dar conta de cobrir os riscos inerentes às mais diversas formas de circulação de capital. No mundo feudal, no qual a riqueza estava atrelada à posse da terra, os ativos não circulavam e as pessoas contavam com os laços familiares, religiosos ou com a solidariedade corporativa nos casos de infortúnios. A exploração marítima que se iniciou na Idade Moderna apresentava novos riscos e eles reclamavam novas formas de proteção ${ }^{8}$. A fonte da moralidade do seguro nasce de um tipo de racionalidade fundada na probabilidade dos infortúnios. A criação de um seguro transforma o que era um obstáculo - o medo da perda - em uma possibilidade objetivamente quantificada. Isso liberta o indivíduo, permitindo que ele possa agir ciente de que, no caso do infortúnio, será ressarcido. Algo que era potencial se torna real pela objetificação criada pelo contrato 9 .

A moralidade do contrato de seguro está construída em torno de quatro valores básicos, que Ewald identificou como sendo: responsabilidade, solidariedade, justiça e

\footnotetext{
${ }^{5}$ Há de se manter a classificação de contrato aleatório mesmo com essas despesas razoavelmente certas, pois algumas pessoas optam por não realizar os exames preventivos e, ainda, não se sabe ao certo os desdobramentos econômicos dos resultados dos exames preventivos, que podem detectar doença grave de alto custo.

${ }^{6}$ CARNEIRO, Luiz Augusto Ferreira. Princípios básicos de seguros e planos de saúde. In: CARNEIRO. LUIZ AUGUSTO FERREIRA (Org.). Planos de saúde: aspecto jurídicos e econômicos. Rio de Janeiro: Forense, 2012, p. 80-2.

${ }^{7}$ Também existem no mercado nacional seguros-saúde ao lado dos planos de saúde. Embora existam algumas diferenças estruturais entre ambos, a legislação nacional os equiparou em termos de limites de cobertura. Ambos os contratos obrigam prestar o mesmo conjunto mínimo de coberturas, de tal sorte que ambos podem ser aqui tratados como uma unidade.

${ }^{8}$ EWALD, François. The values of insurance. Grey room, v. 74, p. 120-145, 2019, p. 120.

${ }^{9}$ EWALD, The values of insurance, p. 129.
} 
verdade $^{10}$. Esses são valores interdependentes e autorreferentes. Eles adquirem um significado especial no contexto dos seguros, permitindo compreender o contrato como um tipo especial de parceria. Esses são valores que possuem uma dimensão política, pois são o resultado de uma escolha social. Uma sociedade fundada em seguros, longe de ser uma sociedade sem valores, é uma sociedade extremamente rígida e virtuosa, que não ignora os riscos que naturalmente decorrem de sua existência ${ }^{11}$. Para Ewald, a história do seguro é uma história que revela a superação da preocupação com a responsabilidade individual para uma compreensão mais ampla da sociedade como um vasto conjunto de $\operatorname{riscos}^{12}$. Vejamos como o autor articulou cada um desses valores.

O valor da responsabilidade busca recordar que as pessoas são responsáveis por suas condutas e atividades, não podendo atribuir aos demais seus fracassos e sofrimentos. Como sofrer infortúnios é algo perfeitamente previsível, cada um deve saber lidar com os riscos que está sujeito. O mundo da previsão é um mundo em que cada pessoa "deve se reconhecer como fraca e frágil, sujeita a intermináveis golpes do destino e a reversões da fortuna"13. Já que os acidentes, além de inevitáveis, podem ser racionalmente previstos, a única opção para o indivíduo responsável é buscar mecanismos para compensá-los. Foi a previsibilidade dos acidentes que criou a demanda por contratos de seguro. Nesses termos, o seguro é uma forma de associação que implementa a previsão e permite que coexistam liberdade de ação e segurança ${ }^{14}$.

Quanto ao valor solidariedade, Ewald recorda que o homem não é nada sozinho, mas é tudo na solidariedade. Deixar de firmar seguros é um erro individual, porque caracteriza um ato de egoísmo e de negligência com sua família, uma forma de deixar de assumir a responsabilidade pela miséria futura. Contratar seguros se torna um tipo de dever social, pois os que não se seguram se tornam um duplo fardo: (a) exigirão assistência social se forem vitimados por acidentes; e (b) os valores que recusaram compartilhar seriam úteis, quando adicionados aos dos outros, para criar um capital para $\operatorname{todos}^{15}$. A ideia de solidariedade típica

\footnotetext{
${ }^{10}$ EWALD, The values of insurance, p. 130.

${ }^{11}$ EWALD, The values of insurance, p. 140-1.

12 BEHRENT, Michael C. Introduction to François Ewald's “The values of insurance”. Grey room. v. 74, p. 112-119, 2019, p. 114-5.

${ }^{13}$ EWALD, The values of insurance, p. 131.

${ }^{14}$ EWALD, The values of insurance, p. 131-2. Como ele destaca: "Em um mundo governado pela previsão, o homem não possui outros recursos além da aritmética e da virtude. Confrontado com a possibilidade de acidentes inevitáveis, o único recurso disponível é aprender a compensá-los" (p. 131).

${ }^{15}$ EWALD, The values of insurance, p. 132.
} 
do direito social surgiu inicialmente no seguro, pois não existe solidariedade sem a responsabilidade individual com o grupo. $\mathrm{O}$ indivíduo não possui apenas uma responsabilidade consigo, mas também com o todo ${ }^{16}$. A solidariedade é um conceito moral: consiste em unir-se nos tempos de infortúnio e não abandonar os necessitados. É nesses termos que o seguro pode ser pensado como um tipo de associação política que transforma o valor das pessoas. Através da associação, as pessoas, que poderiam pensar que não são nada porque muito pequenas, descobrem que equivalem a tudo coletivamente ${ }^{17}$.

Uma das mais importantes características do seguro não é a dispersão dos danos individuais sobre o grupo, mas o fato de que essa distribuição não é entendida como um tipo de ajuda ou alguma forma de caridade. $O$ valor justiça aqui se faz presente, no sentido de que cada pessoa contribuiu prévia e proporcionalmente ao risco causado. O ressarcimento nesses termos é justo, pois a pessoa atingida pelo infortúnio contribuiu segundo seu risco. A escolha do risco torna comparáveis as pessoas e, simultaneamente, revela suas diferenças. Selecionar quais riscos serão assumidos não caracteriza discriminação indevida, sempre que o critério para comparar e diferenciar seja algo determinante para o risco que se pretende segurar $^{18}$.

Finalmente, o seguro não faz concessões com o valor verdade. Tornar objetivo o risco assumido impõe a necessidade de avaliar por completo a verdade. Foi essa necessidade que levou ao desenvolvimento da ciência atuarial. Seguradoras que trabalham com dados errados sobre o risco assumido estão fadadas à falência. A verdade impõe que ambas as partes do contrato sejam verdadeiras: a seguradora deve esclarecer aquilo que está assumindo, enquanto o segurado deve declarar todas as informações relevantes sobre o risco que pretende transferir. Há também um componente social na verdade. O seguro se relaciona com uma sociedade que faz do reconhecimento dos riscos um imperativo de natureza moral, um princípio de conduta racional ${ }^{19}$.

Encerrada a digressão a partir de Ewald, o valor solidariedade merece especial compreensão neste trabalho. Os planos de saúde devem ser compreendidos no contexto da saúde suplementar e, nesses termos, como mais um componente de uma rede de proteção social disponível para a população. Nesse ponto, a saúde suplementar passa a gravitar em

\footnotetext{
${ }^{16}$ EWALD, The values of insurance, p. 134.

${ }^{17}$ EWALD, The values of insurance, p. 135.

${ }^{18}$ EWALD, The values of insurance, p. 136-7.

${ }^{19}$ EWALD, The values of insurance, p. 138-40.
} 
torno das políticas gerais de atenção à saúde, embora explorada por particulares e regulamentada pelo Estado. A liberdade de exploração do mercado passa a ser limitada pelos ditames do direito social, fazendo com que o Estado regule esse tipo de vínculo fortemente. Ao transferir o risco de custear eventos em saúde para uma operadora, as pessoas têm maior liberdade para planejar suas vidas familiares. Para quem não deseja esse risco, é preferível um pagamento periódico fixo e "compatível com suas restrições orçamentárias, do que precisar incorrer em despesas de valor expressivo ou acima de suas possibilidades a qualquer momento, sem mínima previsibilidade" 20 . Em suma, embora financiados com recursos particulares, os planos de saúde devem ser considerados como parte da rede de proteção social disponível à população. Como aponta Cechin, "despesas com saúde estão entre as principais causas da ruína financeira de famílias americanas. E a falência financeira de famílias é um problema social grave"21.

\subsection{Calculando o preço devido}

Agora a segunda questão: como é feito o cálculo do valor cobrado dos usuários dos planos. Esse é um tema que se relaciona diretamente com a questão do equilíbrio econômicofinanceiro do contrato, em especial a precificação do risco coberto. A legislação permite que as contraprestações devidas variem de acordo com a idade do beneficiário ${ }^{22}$. O cálculo inicial do prêmio, embora ele sofra modificação regulatória por conta do pacto intergeracional que analisarei mais abaixo, é definido a partir do custo para a prestação dos serviços para cada usuário. Sobre esses valores são acrescidas quantias para fazer frente a despesas administrativas, comerciais, tributárias e, finalmente, para incluir o lucro da operação. Embora contrair doenças seja um evento futuro e imprevisível para cada indivíduo, a

20 ALVES, Sandro Leal. Fundamentos, regulação e desafios da saúde suplementar no Brasil. Rio de Janeiro: Funenseg, 2015, p. 43.

${ }^{21}$ CECHIN, José. Fatos da vida e o contorno dos planos de saúde. In: CARNEIRO, Luiz Augusto Ferreira (Org.). Planos de saúde: aspecto jurídicos e econômicos. Rio de Janeiro: Forense, 2012, p. 196.

22 Art. 15. A variação das contraprestações pecuniárias estabelecidas nos contratos de produtos de que tratam o inciso I e o $\S 1^{\circ}$ do art. $1^{\circ}$ desta Lei, em razão da idade do consumidor, somente poderá ocorrer caso estejam previstas no contrato inicial as faixas etárias e os percentuais de reajustes incidentes em cada uma delas, conforme normas expedidas pela ANS, ressalvado o disposto no art. 35-E (BRASIL. Lei $\mathrm{n}^{\circ}$ 9.656, de 3 de junho de 1998. Dispõe sobre os planos e seguros privados de assistência à saúde, Brasília/DF, 3 de junho de 1998. Disponível em: < http://www.planalto.gov.br/ccivil_03/leis/L9656compilado.htm>. Acesso em: 16 de julho de 2018).

Parágrafo único. É vedada a variação a que alude o caput para consumidores com mais de sessenta anos de idade, que participarem dos produtos de que tratam o inciso I e o $\S 1^{\circ}$ do art. $1^{\circ}$, ou sucessores, há mais de dez anos". 
incidência de doenças em uma população pode ser estatisticamente determinada com boa precisão para cada patologia ${ }^{23}$. A possibilidade de quantificar o risco global é o que torna possível a existência do contrato de seguro, pois permite o cálculo do montante necessário que se deve reunir para fazer frente aos eventos.

A possibilidade de calcular riscos exige algum tipo de homogeneidade entre os usuários dos planos. É por esse motivo que a legislação optou por agrupar as pessoas por faixas etárias, permitindo o cálculo do custo estimado necessário para atender a saúde de cada grupo. Quanto maior a idade, maior a probabilidade de o usuário necessitar de assistência à saúde. Por essa razão, o aumento da idade é um dos fatores de encarecimento das mensalidades cobradas. Estatisticamente, a utilização dos serviços pode ser representada por uma curva "Quase U”. "Crianças normalmente precisam de mais serviços de saúde na fase mais frágil da infância, numa demanda que tende a se reduzir na adolescência, mas que volta a se elevar na fase adulta e acentuar-se à medida que ocorre o envelhecimento" 24 . Especificamente no caso brasileiro:

A utilização de internações hospitalares é alta na primeira idade. Nos anos seguintes é menor e se mantém em patamar baixo até 45 anos de idade. A partir dessa idade as internações crescem exponencialmente. Neste caso, quando se considera a diferenciação por gênero, fica claro que no caso das mulheres a curva dá um salto atingindo um pico na faixa dos 20 a 29 anos, quando ocorre a idade mais fértil. Ressalta-se que a para determinadas populações a faixa etária de 15 a 19 também apresenta elevação, neste caso por conta da gravidez na adolescência. Da mesma forma, na faixa entre 30 a 39 anos, e recentemente ainda em faixas mais elevadas, as mulheres também engravidam, fenômeno associado a mudanças no mercado de trabalho, principalmente. Possivelmente, a depender do nível de educação das mulheres de uma população beneficiária, há deslocamento da utilização de partos para faixas etárias inferiores ${ }^{25}$.

O cálculo do prêmio dentro de grupos muito heterogêneos, como na hipótese de um preço único para todos usuários independentemente da idade, dificultaria a determinação do preço justo, “onerando excessivamente indivíduos com perfil de risco menos agressivo e subdimensionando a contribuição dos segurados mais propensos a gerar sinistralidades" 26 . Os jovens teriam de arcar com preços muito superiores às despesas estatisticamente

\footnotetext{
${ }^{23}$ CECHIN, Fatos da vida e o contorno dos planos de saúde, p. 199. Como arremata o autor na mesma página, "A estatística nos informa quantos e com que gravidade, mas não poderá identificar quem. Por exemplo, o INSS paga todos os meses cerca de 1,2 milhão de auxílios-doença, o que corresponde a determinado percentual da população ocupada com carteira assinada. Com essa informação, o INSS pode projetar quantos auxíliosdoença deverá pagar a cada mês no futuro, mas não terá como saber a priori quem serão esses indivíduos".

${ }^{24}$ ALVES, Fundamentos, regulação e desafios da saúde suplementar no Brasil, p. 47.

${ }^{25}$ ALVES, Fundamentos, regulação e desafios da saúde suplementar no Brasil, p. 48.

${ }^{26}$ ALVES, Fundamentos, regulação e desafios da saúde suplementar no Brasil, p. 47
} 
esperadas. Como resultado, "poucos seriam os jovens dispostos a se proteger contratando um plano, ao contrário dos idosos. $\mathrm{O}$ 'prêmio nivelado' traz como consequência a seleção adversa não sendo possível, em um mercado privado, seu oferecimento"27. Dito de outra forma, a média do preço será mais alta para os jovens e menor do que o risco dos idosos. Isso cria incentivos para que os jovens saudáveis não contratem planos de saúde e para que os idosos os contratem. É nessa cadeia de incentivos que surge a tendência à seleção adversa: "entre os jovens haveria maior estímulo a contratar o plano ou seguro por parte das pessoas em pior estado de saúde ou que tivessem uma baixa autoavaliação desse seu estado"28. A consequência desse eventual arranjo institucional é o de que "o custo médio ou o risco do conjunto dos que o contratarem ficará maior do que o custo médio para toda a população, falsificando o cálculo inicial do preço ou prêmio. O resultado previsto pela teoria é o aumento do prêmio e a exclusão de pessoas" ${ }^{29}$.

Existem outros fatores, além da idade, que impactam na determinação do preço devido à operadora de plano de saúde. Os preços podem variar a depender do tipo de plano contratado $^{30}$, amplitude de cobertura ${ }^{31}$, rede de prestadores de serviço ${ }^{32}$, tipo de acomodação, presença de reembolso, coparticipação do usuário e a modificação do comportamento do usuário após a contratação do plano ${ }^{33}$, entre outros fatores. Não é meu objetivo aqui analisar

${ }^{27}$ ALVES, Fundamentos, regulação e desafios da saúde suplementar no Brasil, p. 53.

${ }^{28}$ CECHIN, Fatos da vida e o contorno dos planos de saúde, p. 216. Podemos definir genericamente seleção adversa como "como a entrada, numa determinada classe de risco de seguro, de segurados com risco muito acima da média dos demais anteriormente presentes ou com risco muito acima daquele previsto nas premissas atuariais. A seleção adversa tende a ocorrer com mais frequência quando a classificação dos segurados por perfil de risco, por algum motivo, não é devidamente feita pela seguradora ou quando os potenciais segurados tendem a contratar o seguro somente quando sabem que tem grande chance de precisar da cobertura" (ALVES, Fundamentos, regulação e desafios da saúde suplementar no Brasil, p. 78).

${ }^{29}$ CECHIN, Fatos da vida e o contorno dos planos de saúde, p. 216.

${ }^{30}$ Individual, coletivo por adesão ou coletivo empresarial. O primeiro tende a ser o de maior custo em razão da seleção adversa e da tendência estatística de maior utilização. Os demais tendem a ter menores custos em razão de menor frequência de utilização. "Colocando a questão ao contrário, sabe-se que o plano tipicamente desprovido de seleção adversa é o coletivo empresarial, pois no momento da contratação a operadora deve ter o risco dimensionado para a totalidade da massa segurada que, geralmente, está no mercado de trabalho e entram todos de uma única vez, minimizando o risco de escolhas e entradas oportunistas. Não por outra razão, esta modalidade possui um preço mais baixo. No contrato de adesão, por exemplo, há a necessidade de pertencimento a um grupo pré-determinado, definido na regulamentação. A escolha do plano se dá com menos seleção adversa que no plano individual" (ALVES, Fundamentos, regulação e desafios da saúde suplementar no Brasil, p. 54).

${ }^{31}$ Planos com cobertura ambulatorial, hospitalar com ou sem obstetrícia e odontológica.

${ }^{32}$ Aspectos geográficos impactam nesses custos, pois hospitais e laboratórios em grandes centros urbanos tendem a ter maiores custos de manutenção.

${ }^{33}$ A ideia aqui relevante é a do risco moral. O exemplo clássico de risco moral no contrato de seguro é a mudança no comportamento do dono de um carro que, após a celebração do contrato, passa a estacionar o veículo em lugares menos seguros, ciente de que será indenizado no caso de sinistro. $\mathrm{Na}$ área da saúde suplementar, o risco moral vem associado com a utilização excessiva ou desnecessária dos serviços 
como as diversas combinações entre esses elementos impacta os custos do contrato. Para meu argumento inicial, basta que o leitor tenha em mente que planos com ampla rede de hospitais, laboratórios, com hospedagem em quarto individual, com opção de reembolso, sem coparticipação e utilizados desnecessariamente tendem a exigir contraprestações mais elevadas por parte do usuário. Cada incremento contratual eleva os custos para a prestação dos serviços e esses custos são sempre precificados e repassados ao usuário contratante. No Capítulo 4 analisarei com mais detalhes um aspecto que impacta especialmente a gramática de funcionamento do contrato: o desenvolvimento de novas tecnologias em saúde.

A possibilidade de precificar o custo de operação também exige analisar aquilo que a operadora está se obrigando a prestar. Por força da regulação, as operadoras têm a obrigação de cobrir toda e qualquer doença constante na Classificação Estatística Internacional de Doenças e Problemas Relacionados com a Saúde da Organização Mundial de Saúde, porém - e esse é o grande ponto do debate - não estão obrigadas a cobrir todo e qualquer procedimento recomendado pela comunidade médica para seu tratamento. Os limites dos procedimentos com previsão de custeio são os determinados coativamente na regulação ou livremente pactuados através de contrato. Não é possível precificar corretamente os custos de operação sem determinar, com clareza, quais são os procedimentos cobertos. A ampliação desse rol, quer por via da regulação, quer por determinação judicial, tem impacto direto e imediato no equilíbrio econômico-financeiro da relação entre usuários e operadoras. O modelo universal de cobertura ataca exatamente esse ponto do contrato. Ele parte da premissa de que as legítimas expectativas do consumidor impõem a relativização da natureza do rol de coberturas. $O$ tema é polêmico e será analisado no próximo capítulo. Basta ao leitor ter em mente que esse tipo de proposição desafia um ponto absolutamente central da gramática de funcionamento do contrato: a necessidade de precificar os limites das obrigações a partir de um conjunto de regras claras que permita a atividade atuarial. Sem essa possibilidade, a opção que resta às operadoras é o aumento geral dos preços para todos os usuários, aumentando a reserva para despesas e tornando, por consequência, mais oneroso o contrato para todos os consumidores ${ }^{34}$.

contratados. A alteração do comportamento do usuário impacta o cálculo do mutualismo contratual, afetando a solidariedade que se estabelece entre usuários do mesmo perfil de risco. A coparticipação é mecanismo para lidar com o risco moral, pois exige do usuário que participe do pagamento dos procedimentos que utilizará, reduzindo os incentivos para o uso excessivo.

${ }^{34}$ O Ministro Marco Aurélio Mello chama de jurisprudência paternalista esse tipo de decisão. Em suas palavras: "Sob esse rótulo, estão enquadradas decisões que implicam o afastamento dos limites de cobertura previstos 
Acima fiz referência à criação de grupos homogêneos, reunidos em torno da idade de seus membros, como mecanismo para o cálculo do prêmio devido às operadoras. Afirmei que cada grupo ficaria responsável por pagar proporcionalmente os riscos gerados. Essas ideias devem ser corretamente qualificadas, pois sofreram intervenção regulatória importante. Atualmente os grupos etários estão divididos em 10 faixas distintas. A primeira faixa reúne os jovens dos 0 aos 18 anos de idade. As oito faixas subsequentes agrupam os usuários dos planos em intervalos de 5 anos. A última faixa reúne as pessoas com 59 anos de idade ou mais ${ }^{35}$. A forma pela qual o risco é distribuído entre as faixas deve respeitar três regras distintas: (a) o valor fixado para a última faixa etária não poderá ser superior a seis vezes o valor da primeira; (b) a variação acumulada entre a sétima e a décima faixas não poderá ser superior à variação acumulada entre a primeira e a sétima faixas; e (c) as variações por mudança de faixa etária não podem apresentar percentuais negativos ${ }^{36}$. Essas regras são a positivação do chamado pacto intergeracional. O efeito prático da estrutura é o financiamento de parte dos custos das últimas faixas pelos usuários das primeiras, ou seja, os mais jovens pagam por seus planos de saúde valores superiores, financiando parte do custo dos planos dos idosos. Esse financiamento se torna mais evidente quando se percebe que a última faixa reúne usuários muito heterogêneos, pois engloba pessoas com 60, 70, 80 e 90 ou mais anos de idade. Os custos com saúde em cada uma dessas idades divergem muito, embora todas elas tenham sido reunidas dentro da mesma faixa. O pacto intergeracional, portanto, é um sistema de subsídios entre faixas etárias, pois:

as faixas de menor risco (no caso, os jovens) pagam prêmios mais elevados, com objetivo de se financiar parte do custo dos idosos. E mesmo dentre os

nos contratos privados de assistência à saúde até quando são devidamente informados ao contratante, com clareza e destaque na redação - consoante determinação do Código de Defesa do Consumidor -, e adequados à contrapartida financeira devida por este. Em tais situações, entender que as operadoras são obrigadas a prestar qualquer coisa de que o cliente necessite acaba por levar à ruptura do equilíbrio econômico-financeiro dos referidos contratos, situação que, embora favoreça o indivíduo que pleiteou a intervenção judicial, pode prejudicar o universo de beneficiários do plano, caso a seguradora não possua condições financeiras de arcar com os custos" (MELLO, Marco Aurélio. Saúde Suplementar, segurança jurídica e equilíbrio econômicofinanceiro. In: CARNEIRO, Luiz Augusto Ferreira (Org.), Planos de saúde: aspecto jurídicos e econômicos. Rio de Janeiro: Forense, 2015, p. 7-8).

${ }^{35}$ De forma mais clara, estas são as 10 faixas segundo a Resolução Normativa no 63/2003 da ANS: (1) 0 a 18 anos; (2) 19 a 23 anos; (3) (3) 24 a 28 anos; (4) 29 a 33 anos; (5) 34 a 38 anos; (6) 39 a 43 anos; (7) 44 a 48 anos; (8) 49 a 53 anos; (9) 54 a 58 anos; (10) 59 anos ou mais (BRASIL. Resolução Normativa $n^{\circ} 63$ da Agência Nacional de Saúde, de 22 de dezembro de 2003. Define os limites a serem observados para adoção de variação de preço por faixa etária nos planos privados de assistência à saúde contratados a partir de $1^{\circ}$ de janeiro de 2004, Brasília/DF, 22 de dezembro de 2003. Disponível em: <http://www.ans.gov.br/component/legislacao/ ?view=legislacao\&task=TextoLei\&format=raw\&id=NzQ4>. Acesso em: 20 de julho de 2018).

${ }^{36}$ Art. $3^{\circ}$ da Resolução Normativa $n^{\circ} 63 / 2003$ da ANS. 
idosos há subsídio entre as idades, pois todos pagam o mesmo valor, apesar dos mais idosos mais velhos gerarem custos bastante mais elevados ${ }^{37}$.

A sustentabilidade do modelo depende da manutenção de uma certa proporção de beneficiários, com idades inferiores a 59 anos, para cada beneficiário não ativo com essa idade ou mais. Esse é um ponto que demandará atenção no futuro próximo. Há estudos demográficos demonstrando que essa relação está ameaçada por conta da maneira pela qual a transição demográfica brasileira está se realizando. Em outros países, a transição de um país predominantemente de jovens para um país de idosos ocorreu de forma mais gradual, permitindo adaptações progressivas. No Brasil, e esse é um fenômeno de países em desenvolvimento, a transição está se dando de maneira muito acelerada, colocando em risco, entre outros temas, a sustentabilidade do pacto intergeracional ${ }^{38}$. Como alerta Cechin: a “conclusão é inescapável: o presente esquema de financiamento dos idosos pelo pacto entre gerações não é sustentável no tempo. É que não haverá jovens em número suficiente para subsidiar os planos de saúde de tantos idosos que existirão" 39 . Embora a questão demográfica não seja relevante para o tema colocado no trabalho, parece-me importante o leitor compreender como a composição de preços por faixa etária é determinada na regulação brasileira e como o modelo deverá enfrentar novos desafios decorrentes do envelhecimento da população. A afirmação tão comumente repetida de que os planos de saúde são caros para os idosos não leva em consideração que existe um pacto geracional que subsidia diretamente o preço pago por essa população e, o que é pior, que esse pacto está fadado à insustentabilidade econômica. A tendência, portanto, é a de que os planos de saúde se tornem ainda mais onerosos nos grupos de maior idade. Há de se esperar, assim como ocorre com a questão previdenciária, grandes debates e modificações nas regras institucionais que disciplinam o contrato de plano de saúde.

Em suma, encerrando esta breve introdução, o leitor deve ter em mente dois pontos básicos da gramática de funcionamento dos contratos de planos de saúde: (a) ele é valioso para os participantes da prática jurídica porque permite transferir onerosamente um determinado risco, fornecendo um mecanismo de socorro no caso de infortúnio e, simultaneamente, liberando parte dos recursos do usuário para outras finalidades; e (b) a assunção do risco pressupõe clareza naquilo que a operadora está assumindo, clareza que

\footnotetext{
${ }^{37}$ CARNEIRO, Princípios básicos de seguros e planos de saúde, p. 91.

38 Para uma análise mais detida do tema, vide CECHIN, Fatos da vida e o contorno dos planos de saúde, p. $220-1$.

${ }^{39}$ CECHIN, Fatos da vida e o contorno dos planos de saúde, p. 221.
} 
permite, através de cálculos atuariais, a precificação daquilo que os usuários utilizarão dos valores arrecadados pelo grupo. Qualquer interpretação que ignorar esses dois pontos será uma interpretação sem ajuste com a gramática básica de funcionamento desse contrato. Será, portanto, uma interpretação equivocada da prática jurídica. 


\section{CONCLUSÕES}

O objetivo desenvolvido por este trabalho foi o de analisar as diversas categorias normativas que conferem sentido à gramática de funcionamento do contrato de plano de saúde. O projeto foi desenvolvido sob a premissa de que há uma incompreensão no funcionamento desse contrato, incompreensão que pode ser reconduzida à articulação imprecisa de parte dos pressupostos normativos que governam a prática. Dentro de um conjunto mais amplo de incompreensões, pareceu-me importante debater aquela que considero a mais relevante: os limites de cobertura do contrato, pois esse é um tema que está diretamente relacionado com a ideia de adimplemento perfeito. As pessoas celebram contratos para receber serviços de saúde no caso de infortúnio. Essa é, portanto, a causa final (para usar um vocabulário aristotélico) da contratação tomada como um produto do exercício da razão prática. O desacordo sobre aquilo que o usuário pode exigir, pela simples qualidade de contratante dos serviços, é um desacordo relevante que tem recebido respostas conflitantes da doutrina e da jurisprudência brasileiras.

A metodologia jurídica desenvolvida por Ronald Dworkin, pelas razões que apresentei no primeiro capítulo, parece-me a melhor descrição da maneira pela qual nossa prática se desenvolve. A intenção da pesquisa foi a de reposicionar os temas mais relevantes capazes de interferir na questão dos limites de cobertura dentro desse modelo analítico. Compreender o que está em debate, a partir dos limites descritivos dos paradigmas relevantes e dos limites normativos das razões de moral política que lhes confere sentido, foi a estratégia para contrastar as três proposições que concorrem para a determinação da resposta certa para a pergunta colocada. Se o primeiro capítulo teve um adversário teórico, ele pode ser identificado como a vertente positivista pressuposta na chamada constitucionalização do direito civil e, por que não, na própria teoria do direito civil constitucional. Ocupei-me, por muitas páginas, da questão da melhor metodologia para a compreensão da prática jurídica. Não o fiz por preciosismo intelectual, mas por acreditar que essa teoria falha exatamente por uma falta de clareza nos planos da ontologia e da metodologia jurídicas. Embora o debate tenha se tornado, em muitos momentos, excessivamente teórico, ele é um debate com importantes consequências práticas, em especial no plano da interpretação. Como pretendi ilustrar com a análise do modelo de cobertura universal, pressupostos metodológicos equivocados podem nos conduzir a interpretações incorretas da prática jurídica. $\mathrm{O}$ apelo 
apressado a conceitos indeterminados, tais como dignidade da pessoa humana, eficácia horizontal das normas fundamentais, função social, solidariedade e tantas outras, sem levar em consideração todos os pormenores que interferem na maneira pela qual a prática pode se desenvolver, de regra leva a interpretações sem amparo na melhor compreensão do desenvolvimento do direito.

Os demais capítulos foram dedicados à articulação dos paradigmas relevantes para a questão colocada das melhores justificativas de moral política que lhes confere sentido. No segundo capítulo, apresentei as teorias que pretendiam justificar moralmente o que torna a prática contratual valiosa. Duas premissas metodológicas cumpriram um importante papel nesse objetivo. A primeira é a de que o conceito de contrato é um conceito do tipo interpretativo, ou seja, um conceito cujo funcionamento depende da compreensão de suas melhores justificativas morais. A segunda é a da pluralidade dos jogos de linguagem que compõem práticas complexas como o direito em geral e o direito dos contratos em especial. Essas duas premissas permitem considerar que não faz sentido tentar interpretar todos os contratos a partir dos mesmos paradigmas e das mesmas justificativas morais. Reunimos diversos tipos de práticas que reconhecemos como contratuais sob o mesmo rótulo de “contrato" por suas semelhanças de família, mas não pela existência de alguma essência que os torne idênticos.

No plano das melhores justificativas morais para a prática contratual, comecei apresentando dois conceitos estruturantes: os conceitos de justiça comutativa e de justiça distributiva. Afirmei que esses conceitos interpretativos adquirem sentido concreto dentro do contexto da prática na qual são empregados. A justiça distributiva, embora não possa ser considerada como um fundamento geral do direito privado, pertence à gramática fundamental de funcionamento do contrato de plano de saúde. Em seguida apresentei dois modelos o que pretendem justificar a prática contratual a partir do liberalismo. O primeiro deles, desenvolvido por Charles Fried, tentava defender o valor liberdade, ao sustentar que os contratos são tipo especial de promessa. Para o autor, os contratos vinculam porque as promessas devem ser cumpridas. O segundo deles, desenvolvido por Dori Kimel, faz uma distinção muito importante entre as práticas promissórias e as contratuais. O argumento é o de que as práticas promissoras buscam desenvolver algum tipo de relacionamento especial entre as pessoas, enquanto as práticas contratuais são valiosas ao permitir que desconhecidos possam contratar sem se preocupar com os predicados pessoais da parte contrária. O que torna valiosa na prática contratual, portanto, é exatamente a possibilidade de permitir que estranhos cooperem sem ter de levar em consideração os atributos íntimos da outra parte. 
Outro ponto relevante do liberalismo de Kimel está na maneira pela qual ele justifica, a partir do valor liberdade, as diversas formas de intervenção do Estado na autonomia privada. O autor reconhece que, em contexto de disparidades de força, o Estado deve interferir nos contratos, não para limitar a liberdade dos contratantes, mas para assegurar uma forma substantiva de autonomia pessoal. Esse é um argumento muito próximo do outro conjunto de justificativas que tenta dar sentido moral para a prática contratual, tal seja, o welfarismo. Essa teoria, desenvolvida a partir do surgimento dos Estados de bem-estar social, reconhece que o mercado não é um espaço neutro, nem que exista uma forma natural de mercado. Todo desenho institucional que permite o funcionamento do mercado gera efeitos distributivos. Assim, em contextos de disparidade de forças, justifica-se a edição de regras para proteger a parte que se encontra na posição mais fraca, quer pela disposição cogente de cláusulas contratuais, quer pela criação de cláusulas gerais protetivas para dar conta da complexidade da vida social. É possível perceber, portanto, que o valor de moral política que servirá como fundamento de um determinado contrato dependerá do seu contexto, em especial da quantidade de liberdade que o sistema jurídico fornece para os contratantes. A decisão de conceder maior ou menor liberdade contratual, ao final, dependerá de um juízo de natureza moral realizado pela comunidade, em especial após uma análise da disparidade de forças entre as pessoas envolvidas na prática. Essa distinção é importante para a questão, pois a existência de um rol de cobertura mínima encontra fundamento moral nas teorias welfaristas. A possibilidade de ampliar os serviços contratados para além desse mínimo legalmente imposto, por sua vez, possui fonte liberal. Note que apontar a fonte liberal não afasta todas as regras protetivas no plano da interpretação das obrigações assumidas. O welfarismo segue presente durante a execução do contrato, pois a possibilidade de acrescentar serviços não afasta a disparidade de forças entre as partes.

O contrato de plano de saúde possui características dos chamados contratos relacionais. Por esse motivo, o terceiro capítulo foi dedicado à compreensão das principais características paradigmáticas dessa categoria normativa. Rejeitei, pelos mesmos motivos decorrentes da pluralidade dos jogos de linguagem, as pretensões da teoria relacional de servir como uma explicação total para o funcionamento do direito dos contratos, tal como seu autor mais importante, Ian Macneil, passou a defender em seus últimos textos. Essa questão metodológica, contudo, não esvazia as qualidades da teoria como uma descrição adequada de um tipo especial de contrato, tipo articulado em oposição aos contratos que estamos mais acostumados a observar e que foram chamados pelo autor de descontínuos. A categoria dos contratos relacionais desafia muitas características presentes nos contratos 
tradicionais e o contrato de plano de saúde é uma boa ilustração dessas diferenças. Nos vínculos relacionais, o consenso não determina ex ante todo o conteúdo do vínculo obrigacional, mas possui um papel desencadeador de um vínculo de limites razoavelmente indeterminados que se prolongará no tempo. O usuário contrata o plano para receber serviços de saúde na eventualidade de um infortúnio, mas não está claro se esse infortúnio o atingirá nem qual tipo de tratamento a atenção à saúde exigirá. Os contratantes não se colocam, tanto no momento da formação do vínculo, como durante a execução do contrato, em posição de competição, ou seja, eles não atuam para barganhar o melhor acordo. A gramática do relacionamento inclui a formação de um tipo de cooperação bilateral, através da qual ambas as partes devem agir positivamente para o sucesso do empreendimento. Isso fica claro, por exemplo, quando as operadoras de saúde anunciam para o mercado de consumo que cuidarão da saúde do usuário e de sua família. As expectativas legítimas geradas pelo contexto da contratação, portanto, incluem expectativas cooperativas para receber e prestar serviços de saúde. O fator tempo introduz uma complexidade no relacionamento que não se faz presente, ao menos na mesma profundidade, nos contratos descontínuos. O conceito de adimplemento perfeito do contrato caminha ao lado do desenvolvimento do conhecimento científico e tecnológico na área da saúde. Tratamentos recomendados e adequados em um certo momento, por conta da evolução do conhecimento científico, podem se tornar obsoletos passados alguns anos. Assim, o contrato de plano de saúde deve adotar uma estrutura flexível que permita adaptação contínua dos termos do contrato, redefinindo constantemente o conceito de adimplemento perfeito. Essa função é desempenhada pela Agência Nacional de Saúde, através do procedimento de atualização do rol de coberturas obrigatórias dos contratos. Essa regulação não deve ser feita apenas em função da atualização da lista de procedimentos, mas também deve levar em consideração os custos que a atualização impõe para a prestação dos serviços e a limitada capacidade de pagamento dos usuários de planos de saúde. O que torna valiosa a alternativa adotada pelo sistema brasileiro é a dispensa da necessidade de renegociação bilateral e constante dos termos do contrato entre usuário e operadora. Exatamente porque existe uma grande disparidade de forças entre essas partes, é importante que o Estado interfira cogentemente na determinação de uma lista mínima de procedimentos.

O quarto capítulo foi dedicado à compreensão dos pormenores econômicos e tecnológicos que condicionam a maneira pela qual os paradigmas relevantes para a compreensão dos planos de saúde operam na sociedade. Essa é uma pretensão que não dispensa equacionar de forma correta como argumentos econômicos podem interferir na 
determinação de argumentos jurídicos. A solução que apresentei foi novamente, ao menos no plano metodológico, dworkiniana. A etapa pré-interpretativa inclui a compreensão dos paradigmas relevantes da prática que se pretende interpretar. Se a prática é econômica, como normalmente ocorre no direito dos contratos, deixar de entender a maneira pela qual a economia e a tecnologia interferem na forma pela qual o paradigma pode operar é compreender as instâncias paradigmáticas de forma incompleta. O argumento, portanto, é o de que não compreendemos corretamente paradigmas econômicos ignorando a economia. Contudo, a interpretação jurídica não é interpretação econômica. Na segunda etapa da interpretação das práticas, a etapa da apresentação das melhores razões de moral política que justificam a existência e conferem sentido ao funcionamento dos paradigmas, a economia deve abandonar o palco interpretativo, permitindo que os valores morais que a comunidade imputa à prática determinem o sentido da interpretação. A eficiência não é o único nem o mais importante valor prezado pela comunidade.

Os contratos de planos de saúde são contratos, pela importância da área social na qual atuam, fortemente regulamentados pelo Estado. Apresentei as justificativas econômicas e não econômicas para a necessidade de regulação na saúde suplementar. A justificativas econômicas são aquelas que destacam a necessidade de corrigir falhas do mercado e garantir que a competição entre os agentes econômicos aumente o leque de opções de contratação para o consumidor. As justificativas não econômicas recordam que a saúde suplementar é um importante componente das políticas de direito social e, por esse motivo, a regulação é importante para proteger algum nível de solidariedade social e os direitos básicos dos usuários de planos de saúde.

No plano econômico, apontei alguns dos principais fatores de aumento de custos na área da saúde. $\mathrm{O}$ envelhecimento das sociedades alterou o perfil epidemiológico das patologias mais comuns. Enquanto no passado morria-se mais por doenças infectocontagiosas, hoje as populações sofrem com doenças crônicas, doenças que não têm cura, requerem tratamentos complexos, contínuos e de alto custo. Ademais, é um fato inafastável da vida que o aumento da idade dos usuários naturalmente importa maiores custos na atenção à saúde, razão pela qual, por exemplo, o valor dos planos varia por faixaetária. Embora o envelhecimento seja uma conquista da civilização, ele cria pressões econômicas no aumento dos custos para a prestação dos serviços, questões que devem ser pensadas e equacionadas pela sociedade. Existem outros fatores relevantes, como o aumento das despesas em saúde acima da inflação e da renda das pessoas, a possibilidade de os profissionais da saúde induzirem demanda inexistentes e a própria judicialização da saúde. 
O tema mais importante para o trabalho, considerando o corte teórico realizado, é o da incorporação de novas tecnologias. Diversos estudos constatam que o desenvolvimento de novas tecnologias é um dos maiores responsáveis pelo aumento nos custos da prestação dos serviços de saúde. A incorporação de tecnologia na saúde gera um paradoxo. Enquanto na maior parte dos setores as inovações tecnológicas reduzem custos, na saúde elas possuem o potencial de criar demandas sem a substituição dos procedimentos já existentes. Ademais, a diversidade dos interesses dos atores envolvidos no processo de desenvolvimento de novas tecnologias e de incorporação obriga criar critérios técnicos para alocar de forma mais eficiente os recursos escassos disponíveis. Esse papel tem sido desempenhado pela chamada "medicina baseada em evidências", área de pesquisa que, além de outros objetivos, busca determinar se os novos procedimentos em saúde, a partir dos custos econômicos para a prestação e dos ganhos em termos de saúde para as pessoas atendidas, devem ser incorporados. Análises de custo-efetividade são importantes ferramentas analíticas para comparar as alternativas disponíveis, mas não são capazes de solucionar a questão moral da decisão sobre a incorporação de um determinado procedimento em detrimento de outro em muitos dos contextos.

Discutir como tomar esse tipo de decisão alocativa em contextos de escassez ocupou boa parte do último capítulo. Este é um trabalho de teoria geral do direito privado e, por esse motivo, ocupei-me da descrição da gramática do conflito e das justificativas de moral política que, em um plano ideal, devem fornecer constrangimentos normativos para a tomada de decisão. Evitei dolosamente os debates bioéticos de como adotar critérios técnicos para realizar as escolhas entre as alternativas disponíveis, pois eles me afastariam muito do objeto do trabalho. O ideal da integridade aplicado à atividade legislativa do Estado obriga a apresentação das melhores razões de moral política para justificar o ato editado. As melhores razões de moral política, dentro da teoria de Dworkin, são razões igualitaristas. A virtude soberana de qualquer comunidade política é tratar todos com igualdade de consideração. A legitimidade das decisões da comunidade política depende da demonstração de que a decisão levou em consideração igualmente o direito de todas as pessoas interessadas na decisão. Especificamente quando pensamos na área da saúde, porque os recursos existentes são limitados, o tomador da decisão deve realizar escolhas que, de forma absolutamente inafastável, gera vencedores e perdedores. Realizar esse tipo de análise é o maior desafio da regulação. O modelo do seguro prudente ideal proposto por Dworkin, embora importante para compreender que realizar escolhas a locativas é uma exigência de justiça distributiva, fornece poucos subsídios para a tomada de decisão em contextos mais concretos. 
A maior parte dos sistemas jurídicos, quando se depara com debates morais nem sempre comensuráveis, opta pela adoção de modelos regulatórios procedimentais. Existem boas razões de moral política para justificar a criação de um mecanismo procedimental para a saúde suplementar. O procedimento deve ser compreendido como uma oportunidade de deliberação pública sobre a análise das razões relevantes para a tomada da decisão. Neste ponto, beneficiei-me dos argumentos de Norman Daniels. Para o autor, entre outras condições, a deliberação deve respeitar as condições de publicidade e relevância. A primeira sustenta que todas as razões utilizadas para a tomada da decisão devem estar acessíveis ao público. A segunda afirma que apenas razões reconhecidamente relevantes podem interferir na tomada da decisão. Essas condições são importantes, porque aumentam a percepção da legitimidade da decisão tomada, tornam públicos os compromissos morais assumidos pelo órgão de regulação e, ainda, destacam as dificuldades inerentes à atividade de alocar recursos em contextos de escassez. A atividade deliberativa não opera livre de constrangimentos normativos, pois aquele que se engaja genuinamente na atividade de alocar recursos em saúde, dando conta dos quase infinitos e conflitantes interesses dos usuários interessados, assume, no mínimo, um tipo de responsabilidade pela razoabilidade na decisão. Ele deve utilizar razões que, ainda que não sejam capazes de alcançar um consenso, podem ser reconhecidas mesmo pelos prejudicados como razões substantivamente adequadas para a decisão tomada.

A saúde é um bem de importância moral pelas oportunidades que proporciona, notadamente a manutenção de um leque maior de opções para viver uma vida digna de ser vivida. Essa justificativa moral fornece maior concretude aos valores cooperação e solidariedade que ordenam o funcionamento do contrato de plano de saúde, pois esses valores devem ser compreendidos como orientados para a proteção da saúde entendida nesses termos. Apesar disso, não é possível sustentar que o usuário de planos de saúde pode discutir judicialmente o conteúdo da regulação a partir de quaisquer argumentos, inclusive argumentos de moral política. Não é papel do Poder Judiciário atuar como instância revisora da regulação. Essa é uma proposição que não se ajusta a maneira pela qual o Supremo Tribunal Federal interpreta o papel do Judiciário nessa área, nem apresenta as melhores justificativas de moral política que fornece sentido à prática regulatória. Os juízes não são mais capacitados do que os reguladores para analisar as complexas questões envolvidas na esfera da saúde suplementar. Uma sociedade que permita a revisão pontual e atécnica da regulação não é uma sociedade melhor do que uma sociedade que lhe presta deferência. $\mathrm{O}$ desrespeito a compromissos regulatórios gera consequências negativas tanto no incentivo a 
novos investimentos de agentes privados, como na amplitude do mercado à disposição dos usuários. Assim, ainda que o usuário entenda ser possível contestar moralmente conteúdo da regulação, ao argumento, por exemplo, de que as razões apresentadas pelo regulador não levaram em consideração igualmente o interesse de todos os afetados, sua irresignação deverá ser manifestada pelos meios democráticos adequados, quer na esfera legislativa, quer na esfera de participação no procedimento regulatório.

Destacadas as premissas necessárias, apresentei as razões pelas quais acredito que um modelo de cobertura relacional é a melhor resposta para a questão colocada no início do trabalho.

A proposição que chamei de modelo de cobertura universal não resistiu sequer à etapa descritiva do ajuste com os paradigmas relevantes. Ela foi rejeitada, já no primeiro capítulo, por não cumprir os testes analíticos existentes para a análise das interpretações do empreendimento. Ela tampouco resistiu ao teste da justificação normativa, porquanto, como ficou claro no último capítulo, pensar em justiça distributiva em um contexto de escassez de recursos exige, dentro de um modelo de moral política igualitarista, realizar escolhas e definir prioridades alocativas.

A proposição representada pelo modelo convencional de cobertura possui ajuste descritivos com os paradigmas que ordenam o funcionamento do contrato e encontra amparo em boas razões de moral política. Contudo, como afirmei, é possível ir além dos limites convencionais quando se compreendem interpretativamente os valores que organizam o funcionamento do contrato.

O modelo de cobertura relacional aceita os mesmíssimos paradigmas do modelo convencional, mas lança um desafio no plano das justificativas de moral política. Ele parte da ideia de que os valores da cooperação e da solidariedade nos infortúnios, informados pela importância moral que a proteção à saúde deve receber, autoriza ampliar o rol de cobertura sempre que isso, simultaneamente, não for capaz de violar os paradigmas relevantes de funcionamento do contrato. Isso pode ocorrer sempre que, a partir de critérios definidos a partir da economia da saúde, novos procedimentos de custo-efetividade semelhantes aos já precificados na regulação estiverem disponíveis no mercado. Nesses termos, o modelo sustenta que o usuário tem o direito de receber os procedimentos: (a) previstos na regulação da ANS; (b) previstos contratualmente; e (c) todo e qualquer procedimento não previsto convencionalmente que apresente custo-efetividade semelhante a outro já precificado para a mesma patologia. Essa é uma proposição que simultaneamente amplia a cobertura contratual 
a partir da ideia de comutatividade e respeita a precificação realizada pela operadora no cálculo dos custos para a prestação dos serviços. 


\section{REFERÊNCIAS}

AKERLOF, George A. The market for "lemons": quality uncertainty and the market mechanism. The quarterly journal of economics, v. 84, n. 3, p. 488-500, 1970.

ALVES, Sandro Leal. Fundamentos, regulação e desafios da saúde suplementar no Brasil. Rio de Janeiro: Funenseg, 2015.

ARAÚJO, Denizar Vianna. Medicina baseada em evidências e análise econômica na tomada de decisão em saúde. In: Planos de saúde: aspecto jurídicos e econômicos. Rio de Janeiro: Forense, 2012, p. 157-70.

ATIYAH, Patrick S. The Rise and fall of freedom of contract. Oxford: Clarendon Press, 1979.

BEHRENT, Michael C. Introduction to François Ewald's “The Values of Insurance”. Grey Room, v. 74, p. 112-119, 2019.

BERTRAN, Maria Paula Costa. Justiça e contrato: entre comutar e distribuir. São Paulo: Edusp, 2015.

BIAZEVIC, Juan P. H. O raciocínio jurídico de Neil MacCormick: um estudo comparativo entre legal reasoning and legal theory e rhetoric and the rule of law. São Paulo: Juan Paulo Haye Biazevic, 2017.

. O raciocínio jurídico de Neil MacCormick: pressupostos de teoria geral do direito. In: MACEDO JUNIOR, Ronaldo Porto (Org.). Teoria do direito contemporânea: autores e temas. Curitiba: Juruá, 2017, p. 389-415.

BIX, Brian H. The promise and problems of universal, general theories of contract law. Ratio Juris, v. 30, n. 4, p. 391-402, 2017.

BROWNSWORD, Roger. The Philosophy of Welfarism and its emergence in the modern english law of contract. In: BROWNSWORD, Roger; HOWELLS, Geraint G; WILHELMSSON, Thomas (Orgs.). Welfarism in contract law. Aldershot: Dartmouth, 1994, p. 21-62. 
BULLARD, Alfredo. Análisis económico del derecho. Entre el funcionalismo y la esquizofrenia jurídica. In: Enciclopedia de filosofía y teoría del derecho. México: Universidad Autónoma de México, 2015, p. 737-766.

CAMPBELL, David. Ian Macneil and the relational theory of contract. In: The relational theory of contract: selected works of Ian Macneil. London: Thomson Reuters, 2001, p. 358.

CARLINI, Angélica. Judicialização da saúde pública e privada. Porto Alegre: Livraria do Advogado, 2018.

CARNEIRO, Luiz Augusto Ferreira. Princípios básicos de seguros e planos de saúde. In: CARNEIRO. LUIZ AUGUSTO FERREIRA (Org.). Planos de saúde: aspecto jurídicos e econômicos. Rio de Janeiro: Forense, 2012, p. 67-93.

CECHIN, José. Fatos da vida e o contorno dos planos de saúde. In: CARNEIRO, Luiz Augusto Ferreira (Org.). Planos de saúde: aspecto jurídicos e econômicos. Rio de Janeiro: Forense, 2012, p. 195-225.

CHERNEW, Michael E.; MAY, Dustin. Health care cost growth. In: The Oxford handbook of health economics. Oxford: Oxford University Press, 2012, p. 399-426.

COLLINS, Hugh. Introduction: the research agenda of implicit dimensions of contracts. In: CAMPBELL, David; COLLINS, Hugh; WIGHTMAN, John (Orgs.). The implicit dimension of contract: discrete, relational, and network contracts. Oxford: Hart Publishing, 2003, p. 1-24.

COUTINHO, Diogo R; DA ROCHA, Jean-Paul Veiga. Regulação e controle de preços do setor privado no direito brasileiro: hipóteses de possibilidade - parâmetros jurídicos - a irretroatividade das normas no campo regulatório - formas e limites de atuação do Poder Judiciário. Revista de Direito Administrativo, v. 272, p. 253-281, 2016.

DANIELS, Norman. Justice, health, and health care. In: RHODES, Rosamond; BATTIN, Margaret P.; SILVERS, Anita (Orgs.). Medicine and social justice. Oxford: Oxford University Press, 2002, p. 6-23.

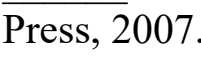

Just health: meeting health needs fairly. Cambridge: Cambridge University

DWORKIN, Ronald. The model of rules I. In: Taking rights seriously. Cambridge: Harvard 
University Press, 1977, p. 14-45.

. The model of rules II. In: Taking rights seriously. Cambridge: Harvard University Press, 1977, p. 46-80.

. Taking rights seriously. In: Taking rights seriously. Cambridge: Harvard University Press, 1977, p. 184-205.

. Can rights be controversial? In: Taking rights seriously. Cambridge: Harvard University Press, 1977 p. 279-290.

. How law is like literature. In: A matter of principle. Cambridge: Harvard University Press, 1985, p. 146-166.

. Is wealth a value? In: A matter of principle. Cambridge: Harvard University Press, 1985, p. 237-66.

. Do We Have a Right to Pornography? In: A matter of principle. Cambridge: Harvard University Press, 1985, p. 335-366.

. Law’s Empire. Cambridge: Harvard University Press, 1986.

$\overline{98,1993 .}$

. Justice in the Distribution of Health Care. McGill Law Journal, v. 38, n. 4, p. 883-

. Law, philosophy and interpretation. ARSP. Archiv. für Rechts-und Sozialphilosophie, v. 80, n. 4, p. 463-475, 1994. 2000, p. $1-7$.

. Does equality matter? In: Sovereign Virtue. Cambridge: Harvard University Press, . Justice and the high cost of health. In: Sovereign Virtue. Cambridge: Harvard University Press, 2000, p. 307-319.

Must our judges be philosophers? Can they be philosophers? Disponível em: <https://web.archive.org/web/20010119034900/http://www.culturefront.org/ culturefront/dworkin.html>. Acesso em: 14 nov. 2018. 
. Objectivity and truth: You'd better believe it. Philosophy \& Public Affairs, v. 25, n. 2, p. 87-139, 1996.

. Introduction: law and morals. In: Justice in robes. Cambridge: Harvard University Press, 2006, p. 1-35.

. In praise of theory. In: Justice in robes. Cambridge: Harvard University Press, 2006, v. 29, p. 49-74.

A virtude soberana. São Paulo: Martins Fontes, 2005.

. Modelo de regras II. In: Levando os direitos a sério. $3^{\text {a }}$ ed. São Paulo: Martins Fontes, 2010, p. 73-125.

. Justice for hedgehogs. Cambridge: Harvard University Press, 2011.

EWALD, FRANÇOIS. A concept of social law. In: TEUBNER, Gunther (Org.). Dilemmas of law in the welfare state. Berlin: European University Institute, 1988, p. 40-75.

. The values of insurance. Grey Room, v. 74, p. 120-145, 2019.

FARIA, José Eduardo. Sociologia jurídica: direito e conjuntura. $2^{\mathrm{a}}$ ed. São Paulo: Saraiva, 2010.

FEINMAN, Jay M. Relational contract and default rules. Southern California Interdisciplinary Law Journal, v. 3, p. 43-58, 1993.

FERRAZ, Octávio Luiz Motta; VIEIRA, Fabiola Sulpino. Direito à saúde, recursos escassos e equidade: os riscos da interpretação judicial dominante. Dados, v. 52, n. 1, p. 223-251, 2009.

FORTES, Paulo Antonio de Carvalho. Orientações bioéticas de justiça distributiva aplicada às ações e aos sistemas de saúde. Revista Bioética, v. 16, n. 1, p. 25-39, 2008.

FRIED, Charles. Contrato como promessa. Rio de Janeiro: Elsevier, 2008. 
. The ambitions of contract as promise. In: LETSAS, George; SAPRAI, Prince;

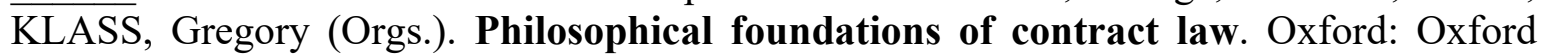
University Press, 2014, p. 17-41.

Contract as promise: A theory of contractual obligation. 2nd ed. Oxford: Oxford University Press, 2015.

GILMORE, Grant. The death of contract. Columbus: Ohio State University, 1995

GLIED, Sherry; SMITH, Peter C. Introduction. In: GLIED, Sherry; SMITH, Peter C (Orgs.). The Oxford handbook of health economics. Oxford: Oxford University Press, 2011, p. 17.

GONÇALVES, Carlos Roberto. Direito civil brasileiro, vol. 3. 15 a ed. São Paulo: Saraiva, 2018.

GORDLEY, James. The moral foundations of private law. The american journal of jurisprudence, v. 47, p. 1, 2002.

Foundations of private law: property, tort, contract, unjust enrichment.

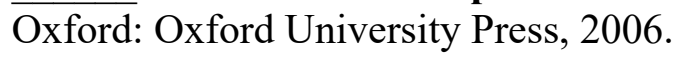

GORDON, Robert W. Macaulay, Macneil, and the discovery of solidarity and power in contract law. Wisconsin law review, v. 1985, n. 3, p. 565-580, 1985.

. Macaulay, Macneil e a descoberta da solidariedade e do poder no direito contratual.

Revista direito GV, v. 3, n. 1, p. 187-202, 2007.

GUEST, Stephen. Ronald Dworkin. Stanford: Stanford University Press, 2012.

HART, Herbert L. A. Definition and theory in jurisprudence. In: Essays in jurisprudence and philosophy. Oxford: Oxford University Press, 1983, p. 21-48.

. The Concept of Law. 2nd. ed. Oxford: Oxford University Press, 1994.

. O Conceito de Direito. Lisboa: Calouste Gulbenkian, 2001. 
Definição e teoria na teoria do direito. In: Ensaios sobre teoria do direito e filosofia. Rio de Janeiro: Elsevier, 2010.

INNERARITY, Daniel; INNERARITY, Carmen. La transformación de la política para gobernar una sociedad compleja. Revista de estudios políticos, n. 106, p. 231-255, 1999.

KIMEL, Dori. From promise to contract: Towards a liberal theory of contract. Oxford: Hart Publishing, 2003.

. The Choice of Paradigm for Theory of Contract: Reflections on the Relational Model. Oxford Journal of Legal Studies, v. 27, n. 2, p. 233-255, 2007.

KRAUS, Jody S. The methodological commitments of contemporary contract theory. University of Virginia school of law working paper, $\mathrm{n}^{\mathbf{0}}$ 01-2, 2001. Disponível em: http://papers.ssrn.com/paper.taf?abstract_id=269975. Acesso em: 23/06/2016.

. The correspondence of contract and promise. Columbia law review, v. 109,

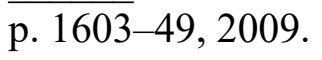

LEVY, Brian; SPILLER, Pablo T. The institutional foundations of regulatory commitment: a comparative analysis of telecommunications regulation. The Journal of Law, Economics, and Organization, v. 10, n. 2, p. 201-246, 1994.

LUCY, William. Philosophy of private law. Kindle Edition. Oxford: Oxford University Press, 2007.

MACAULAY, Stewart. The real and the paper deal: empirical pictures of relationships, complexity and the urge for transparent simple rules. In: CAMPBELL, David; COLLINS, Hugh; WIGHTMAN, John (Orgs.). The implicit dimension of contract: discrete, relational, and network contracts. Oxford: Hart Publishing, 2003, p. 51-102.

MACCORMICK, Neil. Legal reasoning and legal theory. 2nd ed. Oxford: Oxford University Press, 1994.

Rhetoric and the rule of law: a theory of legal reasoning. Oxford: Oxford University Press, 2005.

H.L.A. Hart. 2nd. ed. Stanford: Stanford Law Books, 2008. 
. Retórica e o estado de direito. Rio de Janeiro: Elsevier, 2008.

MACEDO JUNIOR, Ronaldo Porto. Contratos relacionais e defesa do consumidor. $2^{\text {a }}$ ed. São Paulo: Editora Revista dos Tribunais, 2007.

. Apresentação: Ian Macneil e o novo contrato social. In: O novo contrato social: uma análise das relações contratuais modernas. Rio de Janeiro: Elsevier, 2009, p. xxixxxxvi.

. Do xadrez à cortesia: Dworkin e a teoria do direito contemporânea. São Paulo: $\overline{\text { Saraiva }}, 2013$.

A função social do contrato. In: Ensaios de direito privado e social: contratos, meio ambiente e tutela coletiva. São Paulo: Saraiva, 2015, p. 73-80.

. Contrato previdenciário como contrato relacional. In: Ensaios de direito privado

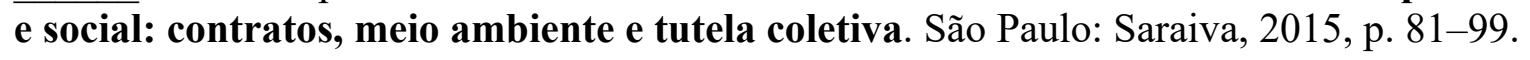

. Interpretação da boa-fé nos contratos brasileiros: os princípios jurídicos em uma abordagem relacional (contra a euforia principiológica). In: Ensaios de direito privado e social: contratos, meio ambiente e tutela coletiva. São Paulo: Saraiva, 2015, p. 115-46.

. Regulação no setor de telecomunicações e o direito do consumidor. In: Ensaios de direito privado e social: contratos, meio ambiente e tutela coletiva. São Paulo: Saraiva, 2015, p. 197-206.

- Teoria contratual e Justiça: um capítulo brasileiro para além da dogmática contratual. In: BERTRAN, Maria Paula (Org.). Justiça e contrato: entre comutar e distribuir. São Paulo: Editora da Universidade de São Paulo, 2015, p. 9-12.

MACNEIL, Ian R. Economic analysis of contractual relations: its shortfalls and the need for a rich classificatory apparatus. Northwestern university law review, v. 75, p. 1018-1063, 1980.

. Values in contract: internal and external. Northwestern university law review, v. 78, p. $340-418,1983$.

. Relational contract: What we do and do not know. Wisconsin law review, v. 1985, 
p. $483,1985$.

Reflections on relational contract. Journal of institutional and theoretical economics, n. 4, p. 541-546, 1985.

. Relational contract theory as sociology: a reply to Professors Lindenberg and de Vos. Journal of institutional and theoretical economics, v. 143, n. 2, p. 272-290, 1987.

. Contracting worlds and essential contract theory. Social \& legal studies, v. 9, n. 3, p. 431-438, 2000.

O novo contrato social: uma análise das relações contratuais modernas. Rio de Janeiro: Elsevier, 2009.

MARQUES, Cláudia Lima. Contratos no Código de Defesa do Consumidor: o novo regime das relações contratuais. $4^{\mathrm{a}}$ ed. São Paulo: Revista dos Tribunais, 2002.

MARTIN, Elizabeth A. (Org.). A dictionary of law. 5th. ed. Oxford: Oxford University Press, 2003.

MCGINN, Marie. Routledge philosophy guidebook to Wittgenstein and the philosophical investigations. London: Routledge, 1997.

MELLO, Marco Aurélio. Saúde Suplementar, segurança jurídica e equilíbrio econômicofinanceiro. In: CARNEIRO, Luiz Augusto Ferreira (Org.). Planos de saúde: aspecto jurídicos e econômicos. Rio de Janeiro: Forense, 2015, p. 3-15.

MICHELON, Claudio. MacCormick's Institutionalism between theoretical and Practical Reason. Diritto \& questioni pubbliche, v. 9, 2009.

. Fundamentos econômicos e não-econômicos da defesa do consumidor. University of Edinburgh, school of law, working papers, v. 2010/11, 2010.

A natureza (pública) do Direito Privado. In: MARTINS-COSTA, Judith; FRADERA, Vera Jacob de (Orgs.). Estudos de direito privado e processual civil: em homenagem a Clóvis do Couto e Silva. São Paulo: Revista dos Tribunais, 2014, p. 61-75. 
materials. Cambridge: Cambridge University Press, 2007.

OGUS, Anthony. Regulation: legal form and economic theory. Oxford: Hart Publishing, 2004.

PERLINGIERI, Pietro. Perfis do direito civil: introdução ao direito civil constitucional. $2^{\mathrm{a}}$ edição. Rio de Janeiro: Renovar, 2002.

POSNER, Eric. Contract theory. In: The Blackwell guide to the philosophy of law and legal theory. Malden: Wiley-Blackwell, 2005, p. 138-47.

POSTEMA, Gerald J. Objectivity Fit for Law. In: LEITER, Brian (Org.). Objectivity in law and morals. Austin: Cambridge University Press, 2001, p. 99-143.

PROSSER, Tony. The regulatory enterprise: government, regulation, and legitimacy. Oxford: Oxford University Press, 2010.

REALE, Miguel. A boa-fé no Código Civil. Disponível em: $<$ http://miguelreale.com.br/artigos/boafe.htm>. Acesso em: 24 maio 2019.

SACKETT, David L; ROSENBERG, William M C; GRAY, J A Muir; et al. Evidence based medicine: what it is and what it isn't. British Medical Journal, v. 312, p. 71-72, 1996.

SCHMITZ, François. Wittgenstein. São Paulo: Estação Liberdade, 2004.

SHAPIRO, Scott. The "Hart-Dworkin" debate: A short guide for the perplexed. University of Michigan public law working paper $\mathbf{n}^{0}$. 77, 2007.

SHIFFRIN, Seana Valentine. Is a contract a promise? In: MARMOR, Andrei (Org.). The Routledge companion to philosophy of law. New York: Routledge, 2012, p. 241-57.

SOUZA, Henrique Freire de Oliveira. Aspectos jurídicos da incorporação da tecnologia em saúde. In: CARNEIRO (Org.). Planos de saúde: aspecto jurídicos e econômicos. Rio de Janeiro: Forense, 2012, p. 121-55.

STAVROPOULOS, Nicos. Objectivity. In: GOLDING, Martin P; EDMUNDSON, William A (Orgs.). The Blackwell guide to the philosophy of law and legal theory. Malden: Blackwell Publishing Ltd, 2005, p. 315-323. 
STIGLER, George J. Law or economics? The journal of law and economics, v. 35, n. 2, p. 455-468, 1992.

SUNSTEIN, Cass R. After the rights revolution: reconceiving the regulatory state. Cambridge: Harvard University Press, 1993.

TRINDADE, Evelinda. A incorporação de novas tecnologias nos serviços de saúde: o desafio da análise dos fatores em jogo. Cadernos de saúde pública, v. 24, p. 951-964, 2008 .

VILLAS-BÔAS, Maria Elisa. Justiça distributiva, critérios de alocação de recursos escassos em saúde e suas críticas. Revista redbioética/UNESCO, v. 1, n. 2, p. 73-84, 2010.

WILHELMSSON, Thomas. The philosophy of welfarism and its emergence in the modern scandinavian contract law. In: BROWNSWORD, Roger; HOWELLS, Geraint G; WILHELMSSON, Thomas (Orgs.). Welfarism in contract law. Aldershot: Dartmouth, 1994, p. 63-96.

WILLIAMSON, Oliver E. The economic institutions of capitalism: firms, markets, relational contracting. New York: The Free Press, 1985.

WITTGENSTEIN, Ludwig. Philosophical investigations. 4th ed. Oxford: WileyBlackwell, 2009. 